\title{
¿Causal Mechanisms of Sea Level and Freshwater Content Change in the Beaufort Sea
}

\author{
ICHIRO FUKUMORI, ${ }^{\mathrm{a}}$ OU WANG, ${ }^{\mathrm{a}}$ AND IAN FENTY ${ }^{\mathrm{a}}$

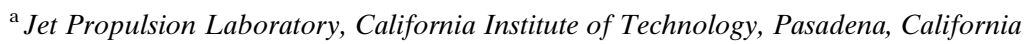

(Manuscript received 25 March 2021, in final form 4 August 2021)

\begin{abstract}
In the Arctic's Beaufort Sea, the rate of sea level rise over the last two decades has been an order of magnitude greater than that of its global mean. This rapid regional sea level rise is mainly a halosteric change, reflecting an increase in Beaufort Sea's freshwater content comparable to that associated with the Great Salinity Anomaly of the 1970s in the North Atlantic Ocean. Here we provide a new perspective of these Beaufort Sea variations by quantifying their causal mechanisms from 1992 to 2017 using a global, data-constrained ocean and sea ice estimate of the Estimating the Circulation and Climate of the Ocean (ECCO) consortium. Our analysis reveals wind and sea ice jointly driving the variations. Seasonal variation mainly reflects near-surface change due to annual melting and freezing of sea ice, whereas interannual change extends deeper and mostly relates to wind-driven Ekman transport. Increasing wind stress and sea ice melt are, however, equally important for decadal change. Strengthening anticyclonic wind stress surrounding the Beaufort Sea intensifies the ocean's lateral Ekman convergence of relatively fresh near-surface waters. The strengthening stress also enhances convergence of sea ice and ocean heat that increase the amount of Beaufort Sea's net sea ice melt. The heightened significance at longer time scales of sea ice melt relative to direct wind forcing can be attributed to the speed at which the Beaufort Sea's semiclosed gyre circulation expels melt water anomalies being slower than the rate of its dynamic adjustment to mechanical perturbations. As a result of such difference, the sea-ice-melt-driven diabatic change will likely persist longer than the direct wind-driven kinematic anomaly.

SIGNIFICANCE STATEMENT: We explore why sea level, a fundamental indicator of climate change, has been rising in the Arctic's Beaufort Sea by almost an inch $(2.54 \mathrm{~cm})$ a year over the last two decades, faster than anywhere else on the globe. We show that this rapid Beaufort Sea sea level rise is caused by a change in wind forcing that alters not only ocean circulation but also the amount of sea ice formed outside the region transported and then melted inside the Beaufort Sea. The region's sea ice meltwater content evolves slowly and is largely confined near the surface, whereas ocean circulation varies more rapidly, and its effect extends deeper into the ocean. Understanding these mechanisms offers new insight into how the ocean might evolve in the coming years.
\end{abstract}

KEYWORDS: Ocean; Arctic; Sea ice; Freshwater; Sea level; Climate variability; Numerical analysis/modeling; Seasonal variability

\section{Introduction}

Over the past few decades, the Beaufort Sea has experienced some of the largest sea level variations across the globe (Giles et al. 2012; Armitage et al. 2016). In particular, satellite observations show that from 2003 to 2017 the rate of sea level rise has exceeded $2 \mathrm{~cm} \mathrm{yr}^{-1}$ over the Beaufort Sea, an order of magnitude larger than the global mean. Studies indicate that this Beaufort Sea sea level rise is mostly steric in nature, associated with a significant increase in the region's upper-ocean freshwater content (Proshutinsky et al. 2009, 2019; McPhee et al. 2009; Rabe et al. 2011). In situ observations, in combination with satellite sea level and ocean bottom pressure measurements, reveal Beaufort Sea's freshwater content increasing at a rate exceeding $400 \mathrm{~km}^{3} \mathrm{yr}^{-1}$ from 2003 to 2018 . The net increase amounts to $40 \%$ of the region's freshwater content in the 1970s, a volume change comparable to that released to the North Atlantic during the

\footnotetext{
D Denotes content that is immediately available upon publication as open access.
}

Corresponding author: Ichiro Fukumori, fukumori@jpl.nasa.gov
Great Salinity Anomaly (Proshutinsky et al. 2019; Dickson et al. 1988). A sudden release of this latest freshwater accumulation would raise the prospect of disrupting large-scale ocean circulation and climate (Proshutinsky et al. 2002).

The cause of Beaufort Sea's recent rise in sea level and freshwater content has been attributed to atmospheric circulation and sea ice melt (Proshutinsky et al. 2002, 2009, 2019; Rabe et al. 2011; Morison et al. 2012; Giles et al. 2012; Krishfield et al. 2014). Change in wind stress alters ocean circulation, including Ekman transport and Ekman pumping, redirecting and collecting fresher water masses in the domain. Variation in sea ice melt further affects the change, because of its lower salinity relative to the ocean. Yet the relative contributions of these elements and their specific mechanism remain uncertain.

For instance, Giles et al. (2012), based on satellite observations and atmospheric reanalysis (Kalnay et al. 1996), demonstrates spatial correlation between trends of sea level and wind curl over the Beaufort Sea between 1995 and 2010,

Publisher's Note: This article was revised on 20 October 2021 to correct two editing errors that appeared in the last sentence of the Conclusions and in the caption to Fig. A4. 
suggesting that the sea level rise reflects increasing Ekman convergence and pumping. However, the sea level and wind lack year-to-year temporal coherence, prompting the authors to hypothesize a stronger coupling between the atmosphere and ocean after 2003 not resolved by the atmospheric reanalysis. In comparison, Proshutinsky et al. (2019) attributes the freshwater content rise between 2003 and 2018 to the nearstationary value of the region's Ekman pumping itself rather than its change, noting similarity between the observed deepening rate of isopycnals and Ekman pumping inferred from the same reanalysis (Kalnay et al. 1996). Yet the correspondence between isopycnal depth and Ekman pumping becomes incoherent after 2010, suggesting of additional processes at work.

Indeed, Krishfield et al. (2014), analyzing property budgets of the ocean and sea ice based on observations from 2003 to 2012, estimates an increasing Beaufort Sea sea ice melt making significant contributions to the region's freshwater content, contributing as much as $15 \%-18 \%$ to the latter's rapid rise between 2006 and 2008. Based on hydrochemistry, Morison et al. (2012), however, suggests sea ice production and export exceed melt in the Beaufort Sea, and instead attributes the region's 2005-08 freshwater content rise to Eurasian runoff redirected across the Arctic Ocean by changes in large-scale atmospheric circulation (Thompson and Wallace 1998). Lateral water mass exchange associated with ocean eddies could also affect the region's freshwater content. For example, Armitage et al. (2020) hypothesizes an increase in mesoscale eddy activity due to steepening stratification to explain an apparent stabilization of the region's sea level rise after 2007.

Here, we revisit the nature and causal mechanism of Beaufort Sea's sea level and freshwater content variation over the last three decades, using a data-constrained, global coupled ocean and sea ice state estimate of the Consortium for Estimating the Circulation and Climate of the Ocean (ECCO). ECCO's model-data synthesis provides a coherent description of the ocean and sea ice, allowing explicit quantification of processes underlying the coupled system. In sections 2 and 3, we describe the state estimate and its fidelity in resolving observed variations of the Beaufort Sea. Mechanisms responsible for the change are explored in sections 4 and 5 by identifying contributions of individual forcings and analyzing controlling processes. We conclude by summarizing our findings in section 6 .

\section{ECCO, version 4, release 4 (V4r4)}

ECCO synthesizes nearly all extant observations of the ocean and sea ice across the globe with a state-of-the-art coupled ocean-sea ice model (Wunsch et al. 2009). The synthesis's comprehensive description of the time-evolving ocean and sea ice state allows analyses that are difficult to conduct from commonly sparse and/or intermittent observations alone. Moreover, in contrast to conventional data assimilation, ECCO's smoothed estimate, in the terminology of estimation theory (Wunsch 2006), is physically consistent in that the state's temporal evolution can be ascribed entirely to first principles, a feature that is fundamental to the present study. For instance, property budgets can be closed, without extraneous "data increments," in terms of explicit physical processes that are estimated in addition to the state. These processes provide insight into mechanisms governing the ocean whose variation is often a sum, or residual, of a number of competing elements. ECCO's model, including its adjoint, permits interrogation of these elements that is often challenging to do solely with the state in and of itself.

In this study, we employ the ECCO, version 4, release 4, estimate and modeling system (V4r4). V4r4 represents ECCO's latest ocean-sea ice state estimate that spans the 26-yr period from 1992 to 2017 (ECCO Consortium 2021). The estimate is based on the Massachusetts Institute of Technology general circulation model (MITgcm; Marshall et al. 1997) with a prognostic dynamic and thermodynamic sea ice model (Losch et al. 2010). Version 4 is ECCO's first truly global, multidecadal description of the ocean and sea ice that includes the Arctic Ocean (Forget et al. 2015). The model has 50 vertical levels spanning the entire water column with $10-\mathrm{m}$ resolution near the surface, and a horizontal resolution ranging from approximately $41 \mathrm{~km}$ in the polar regions to $111 \mathrm{~km}$ in temperate latitudes that telescopes again meridionally to $44 \mathrm{~km}$ in the equatorial domain. The model uses a nonlinear free-surface formulation and real freshwater flux boundary condition, permitting accurate accounting of sea level and freshwater content change (Campin et al. 2008). Mixing processes are simulated using standard parameterizations with convective adjustments (Redi 1982; Gent and McWilliams 1990; Gaspar et al. 1990).

The coupled model is constrained by satellite observations, such as sea level from altimeters and sea ice concentration from radiometers, and in situ measurements, including hydrographic data from ice-tethered profilers (ITPs) in the Arctic (Toole et al. 2011; Krishfield et al. 2008). Specifically, by formal inversion, version 4's estimation adjusts the model's atmospheric forcing (surface atmospheric state including radiative fluxes), initial condition, and mixing parameters so as to minimize, in a least squares manner, the analysis's difference from observations. [See ECCO Consortium (2021) for a full list of observations]. The limited set of adjusted variables does not signify that there are no other sources of model error but is a simplifying choice in solving for a particular solution of the estimation problem, the veracity of which is demonstrated a posteriori by the result's consistency with observations.

As its prior estimate, V4r4 employs the 6-hourly atmospheric state of the European Centre for Medium-Range Weather Forecasts interim reanalysis (ERA-Interim; Dee et al. 2011). The bulk formula parameterization of Large and Yeager (2004) is employed to evaluate the model's diabatic forcing, while the reanalysis's wind stress is directly utilized as momentum forcing. Atmospheric pressure forcing is applied but not corrected by the model-data synthesis.

In the present study, we also employ a flux-forced version of the model to facilitate analyses of causal mechanisms. The fluxforced model employs V4r4's momentum and diabatic fluxes between the ocean, sea ice, and atmosphere (including radiative fluxes) evaluated and archived at 6-h intervals. The resulting ocean and sea ice states of the two models are virtually identical to each other but, whereas heat and freshwater fluxes are dependent in the bulk-formula version, the two are independent in the flux-forced version, thus permitting unambiguous determination of their individual effects. 


\section{Variations of the Beaufort Sea}

Before exploring processes, we first assess and demonstrate the fidelity of ECCO V4r4 (hereinafter simply ECCO) in resolving variations of the Beaufort Sea by comparing the state estimate with different observations. Relationships among the quantities are also examined so as to ascertain the physical nature of the variation. In this and the following section we focus on the ocean. Sea ice and its interaction with the ocean will be examined in section 5 .

\section{a. Sea level}

Observations reveal large geographic variations of sea level rise. In fact, between 1993 and 2017, the Arctic Ocean has the largest sea level trend across the entire globe (Fig. 1). Here, sea level, including that under sea ice, is defined as dynamic sea level, that is, height of the liquid ocean surface isostatically corrected (inverse barometer) for the loading effect of sea ice, snow, and atmospheric pressure (Griffies and Greatbatch 2012). In this study, we reference sea level to its global mean to distinguish regional variations.

ECCO's large Arctic sea level rise is generally confined to the Beaufort Sea, in particular the deep waters of the Canada Basin, with a maximum $13.4 \mathrm{~mm} \mathrm{yr}^{-1}$ trend (Fig. 2). The region of sea level rise is nearly coincident with the semipermanent anticyclonic Beaufort Gyre, consistent with Giles et al. (2012) who employed special processing of altimeter measurements to detect specular reflections from leads (not utilized in the ECCO estimate). The near-circular region where sea level trend exceeds $6 \mathrm{~mm} \mathrm{yr}^{-1}$ (black contour in Fig. 2a), hereinafter referred to simply as the "Gyre" region, has an area of $907244 \mathrm{~km}^{2}$ and dominates the variation across the Arctic Ocean.

ECCO's sea level anomaly (i.e., deviation from time mean) averaged monthly across the Gyre region (black in Fig. 3a) consists of high-frequency intraseasonal variations with peakto-peak amplitude of about $10 \mathrm{~cm}$ and a larger lower-frequency interannual-to-decadal change in excess of $20 \mathrm{~cm}$. Notably, sea level increases rapidly during the second half of the analysis period compared to the first. For instance, the 1996-2001 trend is $-0.07 \pm 0.20 \mathrm{~cm} \mathrm{yr}^{-1}$ whereas the $2002-09$ trend is $1.80 \pm 0.15 \mathrm{~cm} \mathrm{yr}^{-1}$, comparable to analyses of Giles et al. (2012). ECCO's higher-frequency variations are also consistent with the altimetric analysis of Armitage et al. (2016) (red in Fig. 3a) that also utilizes data not employed in ECCO noted above. ECCO has a correlation coefficient of 0.79 with the Armitage et al. (2016) observation-based analysis and explains $56 \%$ of its variance.

\section{b. Ocean bottom pressure}

A significant fraction of high-latitude sea level variability can be ascribed to intraseasonal barotropic fluctuations (e.g., Fukumori et al. 1998). Indeed, ECCO's ocean bottom pressure averaged across the Gyre region (black in Fig. 3b) consists mainly of intraseasonal fluctuations that account for nearly all of sea level's high-frequency variability (gray). Importantly, however, ocean bottom pressure lacks sea level's decadal variation that was noted above.

ECCO's ocean bottom pressure is consistent with GRACE observations (red in Fig. 3b; Watkins et al. 2015) that were

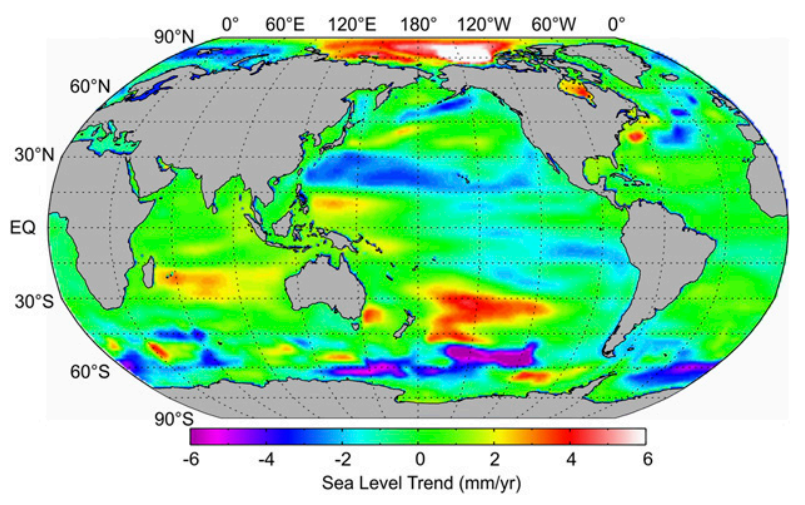

FIG. 1. Geographic variation of ECCO V4r4 sea level trend from 1993 to 2017 relative to its global mean $\left(3.2 \mathrm{~mm} \mathrm{yr}^{-1}\right)$. The trend in the Arctic's Beaufort Sea is in excess of $13 \mathrm{~mm} \mathrm{yr}^{-1}$ and is the largest across the globe. See also Fig. 2, below.

employed in ECCO's estimation, explaining $89 \%$ of the data's variance. Most of this variation can be ascribed to a remotewind-forced, near-uniform barotropic fluctuation spanning the entire interconnected deep-ocean basins of the Arctic Ocean and the Nordic seas that is largely unrelated to changes specific to the Beaufort Sea (Fukumori et al. 2015). Indeed, ocean bottom pressure averaged across these interconnected basins (cyan) is nearly identical to that of the Gyre region (black).

\section{c. Steric sea level and freshwater content}

Differences between sea level and ocean bottom pressure reflect steric effects, which dominate sea level's seasonal-todecadal variation averaged across the Gyre region (Fig. 3c). Formally, in the model, steric sea level (black) explains $84 \%$ of sea level's variance (gray) and $81 \%$ of its overall trend $(6.8 \pm$ $\left.0.2 \mathrm{~mm} \mathrm{yr}^{-1}\right)$. This steric change is almost entirely halosteric (cyan) with negligible thermosteric contributions (red), consistent with other studies (e.g., Morison et al. 2012; Armitage et al. 2016; Proshutinsky et al. 2019).

Halosteric sea level variations reflect salinity $S$ changes, which are often described in terms of freshwater content $\left(S_{\text {ref }}-\right.$ $S) / S_{\text {ref }}$, where $S_{\text {ref }}$ is a reference salinity (e.g., Proshutinsky et al. 2009). Using $S_{\text {ref }}$ of 34.8 PSU, a typical value for Arctic Ocean studies, Fig. 3d compares ECCO's Gyre-integrated freshwater content variations from the liquid ocean surface to the depth of $S_{\text {ref }}$ (black) with analogous observation-based estimates from Proshutinsky et al. (2019) utilizing in situ moorings (red) and ITPs (cyan). ECCO is not constrained by integral freshwater content estimates but does utilize temperature and salinity data from these observing systems at the time and location of the measurements. Significantly, ECCO resolves most of the interannual variation inferred from these data, especially the rapid change from 2004 to 2010.

The mooring-based freshwater content estimate corresponds to an integral from $65 \mathrm{~m}$ down to the 34.8-PSU isohaline and therefore excludes the large seasonal cycle near the surface (Proshutinsky et al. 2019). Indeed, in ECCO, 95\% of the seasonal cycle's variance is explained by variations in the top $55 \mathrm{~m}$ (Fig. 4). Here, and in subsequent discussions, seasonal cycle is 

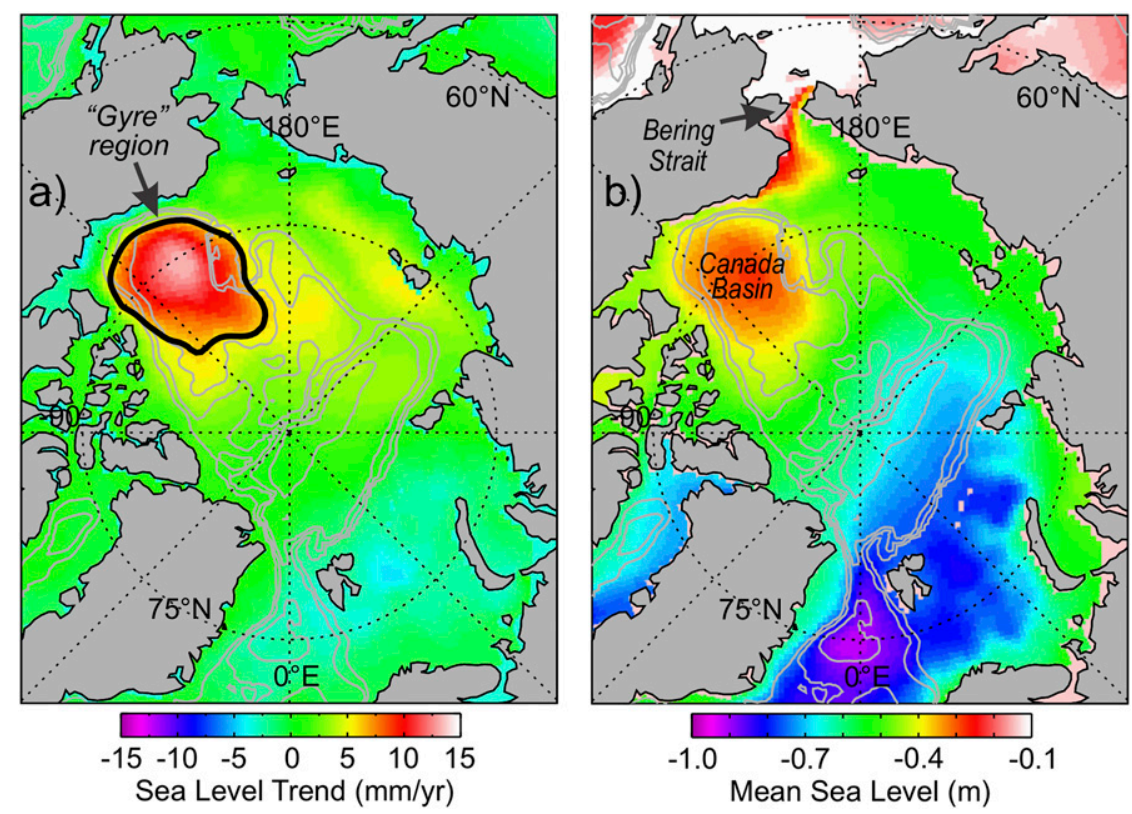

FIG. 2. Sea level variations of the Arctic Ocean in ECCO V4r4: (a) trend and (b) time-mean over 1993-2017. The anticyclonic circulation of the Beaufort Gyre is evidenced in (b) by the doming of the time-mean sea level spanning the Canada Basin. The trend in (a) is relative to its global mean $\left(3.2 \mathrm{~mm} \mathrm{yr}^{-1}\right)$ as in Fig. 1. The black contour in (a) corresponds to a $6 \mathrm{~mm} \mathrm{yr}^{-1}$ trend and outlines the "Gyre" region studied in this investigation; the region has a latitude and longitude range of $71.7^{\circ}-82.1^{\circ} \mathrm{N}$ and $129.0^{\circ}-169.6^{\circ} \mathrm{W}$. Bathymetry is contoured in gray at $1000-\mathrm{m}$ intervals.

defined by the average of each month between 1992 and 2017. In contrast, nonseasonal freshwater content variations extend nearuniformly down to $223 \mathrm{~m}$; variations from the surface to this depth, a depth well above the 34.8 PSU reference isohaline (solid gray in Fig. 4a), explains $95 \%$ of the nonseasonal variations' total variance. Relative to its integral from the surface (black in Fig. 3d), ECCO's equivalent of the mooring estimate between $65 \mathrm{~m}$ and the 34.8-PSU isohaline (gray) has a much smaller seasonal cycle and somewhat weaker interannual variation. ECCO's mooring equivalent (gray) explains $77 \%$ of the mooring-based estimate's variance (red).

Freshwater content estimate from ITPs (cyan in Fig. 3d) has a somewhat larger variation than does the mooring estimate, reflecting in part the fact that the ITP data (from the surface to the 34.8-PSU isohaline) include near-surface variations that the mooring data do not. Forty percent of the ITP estimate's variance (cyan) can be explained by ECCO (black). The state estimate's lesser skill in resolving the ITP estimate's variance relative to that of the mooring may in part be due to uncertainties associated with constructing the regional mean from drifting instruments that typically operate only in icecovered regions (Proshutinsky et al. 2019). For comparison, the mooring estimate (red) and its ECCO equivalent (gray) explain $54 \%$ and $50 \%$ of the ITP estimate's variance, respectively.

\section{d. Summary}

In summary, the ECCO estimate is largely consistent with observed changes of the Beaufort Sea. As the estimate adheres to first principles (section 2), this consistency with observations also provides an indirect validation of the physics within the ECCO model. Hence, in the following sections, we will utilize the model to explore and analyze processes responsible for these observed variations.

\section{Causal mechanisms}

In this section, we investigate the forcings and physical mechanisms responsible for Beaufort Sea's sea level and freshwater content variations by analyzing the ECCO ocean model with a focus on seasonal-to-decadal changes.

\section{a. Forcings and their effect}

We explore controlling elements responsible for the variation by quantifying their individual contributions. Specifically, the ECCO estimate is compared with separate realizations of its flux-forced version of the ocean model (section 2), each with an element removed from a particular control (forcing; state of initial condition). Resulting differences between ECCO and each modified estimate represent contributions of the corresponding removed element.

Figure 5 compares time series of such contributions to ECCO's Gyre-mean sea level variation by anomalies of surface stress (red), surface freshwater flux (cyan), and initial condition (orange). Here, "surface" is the liquid surface of the ocean and "stress" and "freshwater flux" include the ocean's interaction with both atmosphere and sea ice. No single control explains the entire variation (black), but the sum of the three (green) accounts for nearly all (95\%) of ECCO's variance. Contributions 

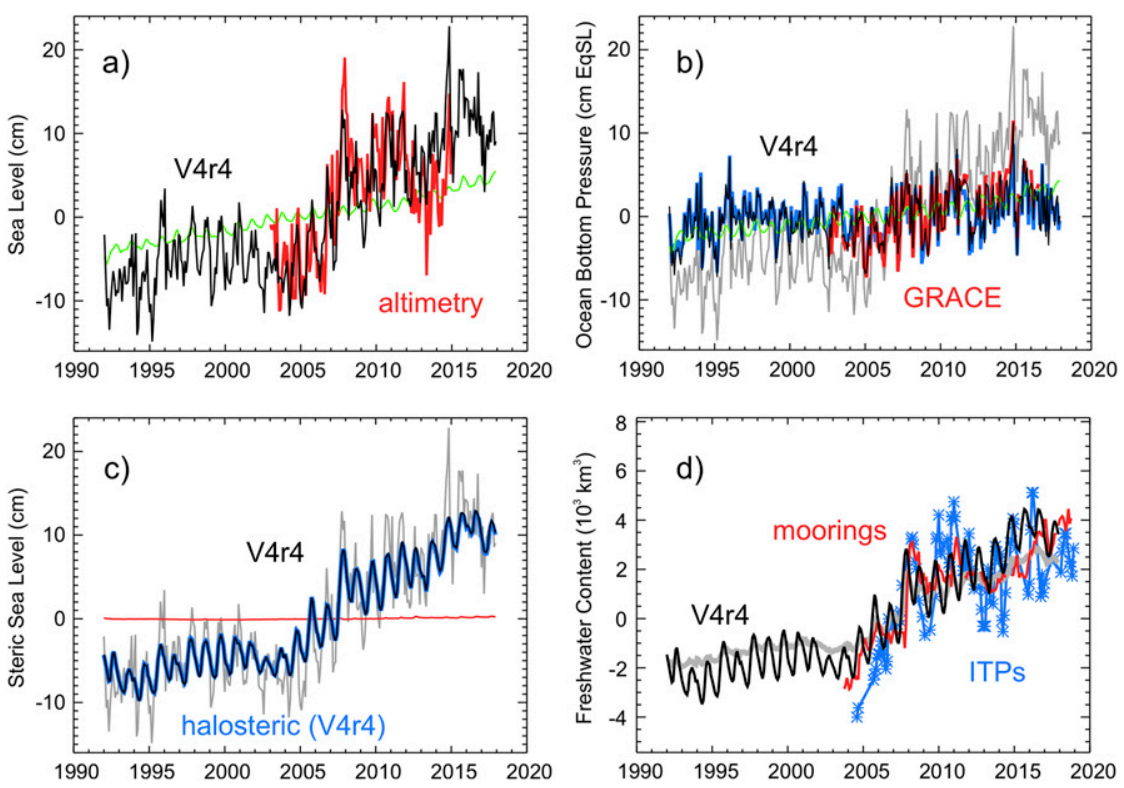

FIG. 3. Monthly mean anomaly time series of the Gyre region described in Fig. 2 for (a) sea level, (b) ocean bottom pressure, (c) steric sea level, and (d) ocean freshwater content. Quantities are area averages in (a), (b), and (c) and volume integrals in (d). Units are centimeters in (a) and (c), centimeters of equivalent sea level (EqSL) in (b), and $10^{3}$ kilometers cubed in (d). ECCO V4r4's respective quantities are shown in black in all panels. In (a), red is the altimetry-based analysis of Armitage et al. (2016), which, along with ECCO, is shown relative to the model's global mean (green). The trend of ECCO's Gyre-mean sea level is $8.4 \pm 0.3 \mathrm{~mm} \mathrm{yr}^{-1}$ relative to that of its global mean $\left(3.24 \pm 0.04 \mathrm{~mm} \mathrm{yr}^{-1}\right)$. In (b), red is GRACE observations; both ECCO and GRACE are referenced to their respective global means. The trend of ECCO's ocean bottom pressure is $1.5 \pm 0.2 \mathrm{~mm} \mathrm{yr}^{-1}$ relative to that of its global mean shown in green $\left(2.19 \pm 0.05 \mathrm{~mm} \mathrm{yr}^{-1}\right)$. ECCO's ocean bottom pressure (black) explains $42 \%$ of its variance in sea level [gray, also shown in (c), is the same as black in (a)]. Cyan in (b) is ECCO's ocean bottom pressure averaged across the interconnected deep-ocean basins of the Arctic Ocean and the Nordic seas, which explains $90 \%$ of its Gyre-mean's variance (black). In (c), cyan and red are ECCO's halosteric and thermosteric sea level, respectively. Panel (d) shows in situ observations of Proshutinsky et al. (2019) for moorings (red) and ITPs (cyan) scaled by $75 \%$ to reflect the smaller area of the present study. Gray in (d) is the model's equivalent of the mooring's estimate. (See the text for the different depths of integration.) The ECCO estimate in black is net freshwater content that corresponds to an integral from the liquid ocean surface to the depth of the reference isohaline $S_{\text {ref. }}$

by other forcings are negligible and, therefore, these three controls are the primary drivers of ECCO's variation, and their effects are linear. Separately, anomalies in surface stress, freshwater flux, and initial condition explain $80 \%, 53 \%$, and $15 \%$, respectively, of ECCO's variance. (The sum of the three exceed $100 \%$ because explained variance is not additive when elements are correlated.) While all three contribute to interannual change, Fig. 5 shows surface stress accounting for most of the intraseasonal variation, reflecting the wind-driven barotropic fluctuation noted in the previous section. Contributions of freshwater flux dominate seasonal change while anomalies in the initial condition, which reflect the forcings' variation prior to 1992, promote a gradual spinup.

The controls' relative impact on seasonal-to-interannual change is evidenced more clearly in terms of freshwater content (Fig. 6) as it is not affected by the intraseasonal winddriven barotropic fluctuation. Here, surface stress, surface freshwater flux, and initial condition explain $71 \%, 67 \%$, and
$19 \%$, respectively, of the freshwater content's variance, and account for $46 \%, 40 \%$, and $14 \%$ of the sum's trend. Seasonal variation, which accounts for $9 \%$ of the freshwater content's total variance, can be ascribed almost entirely $(98 \%)$ to surface freshwater flux, as is the case for sea level.

The three controls also affect freshwater content differently in depth (Fig. 7). Whereas the impact of surface freshwater flux (cyan) is largely confined to the surface $(<60 \mathrm{~m})$, the effect of surface stress (red) extends from the base of this surface layer $(\sim 60 \mathrm{~m})$ to the base of the halocline $(\sim 260 \mathrm{~m})$. Anomalies associated with the initial condition (orange) are confined in depth around the halocline (100-260 m) and are smaller than contributions from surface stress, and, therefore, will not be considered further. Horizontally, in terms of sea level trend (Fig. 8), the effect of freshwater flux is distributed more uniformly over the Gyre region than that of surface stress, indicating that surface stress drives most of the region's change in surface geostrophic current. 


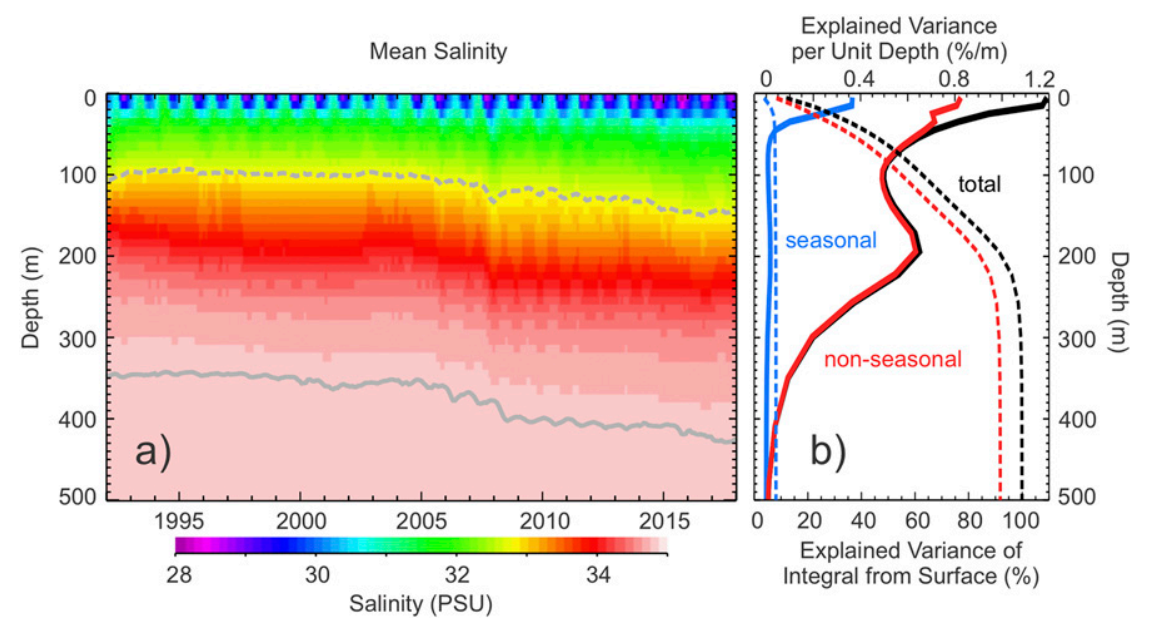

FIG. 4. Variation with depth of (a) salinity and (b) freshwater content in the Gyre region of ECCO V4r4. The temporal change of the mean salinity profile is shown in (a). The dashed and solid gray curves mark the 32.7- and 34.8-PSU isohalines, respectively, with average depths of 112 and $377 \mathrm{~m}$. The variance of net freshwater content change (black in Fig. 3d) explained as a function of depth (solid black curve with axis at top) and as an integral from the surface (dashed black curve with axis at bottom) is shown in (b). Cyan and red are the same but for contributions by the seasonal and nonseasonal components, respectively.

\section{b. Mechanism of the variation}

The causal elements' spatial and temporal variation can further shed light on processes underlying the change. To this end, we explore a linear decomposition of the model's Gyremean sea level anomaly $\delta J$ with regard to anomalies of its independent forcings/controls $\delta \phi_{i}$ at different locations $\mathbf{r}$ and earlier times $t-\Delta t$,

$$
\left.\delta J(t) \approx \sum_{i} \sum_{\mathbf{r}} \sum_{\Delta t} \frac{\partial J}{\partial \phi_{i}}(\mathbf{r}, \Delta t)\right|_{t_{g}} \delta \phi_{i}(\mathbf{r}, t-\Delta t) .
$$

Here, $t$ denotes the instance of the sea level anomaly $\delta J$, subscript $i$ distinguishes different controls $\phi$ (e.g., surface stress and surface freshwater flux), and $\Delta t$ is the temporal lag between $\delta J$ and $\delta \phi$. The gradient coefficient $\partial J /\left.\partial \phi_{i}(\mathbf{r}, \Delta t)\right|_{t_{g}}$ is the sensitivity of $J$ at some particular instance $t_{g}$ to control $\phi_{i}$ at location $\mathbf{r}$ and time-lag $\Delta t$ and is employed as an approximation for this sensitivity at arbitrary instances $t$; namely,

$$
\left.\frac{\partial J}{\partial \phi_{i}}(\mathbf{r}, \Delta t)\right|_{t_{g}} \equiv \frac{\partial J\left(t_{g}\right)}{\partial \phi_{i}\left(\mathbf{r}, t_{g}-\Delta t\right)} \approx \frac{\partial J(t)}{\partial \phi_{i}(\mathbf{r}, t-\Delta t)} .
$$

Employing such approximation is computationally convenient as all the gradients for Eq. (1) can then be evaluated by a single integration of the model's adjoint backward in time from $t_{g}$, instead of the multitude that would be required from different instances of $J$ in a first-order Taylor series expansion. With such approximation, Eq. (1) can be recognized as a convolution between the controls and these particular sensitivities. Unless noted otherwise, $J$ in Eq. (1) is month-long mean of the Gyre region's spatially averaged sea level and $\phi$ denotes weeklyaveraged controls.
Equation (1)'s expansion and sum, termed adjoint gradient decomposition and reconstruction, respectively, quantify contributions to $J$ of each control from different locations at distinct instances based on physical dependencies encapsulated in the model (gradient), and can be an effective means to analyze causal mechanisms (Fukumori et al. 2015). For example, the largest term of the summation on the right-hand side of Eq. (1) can be identified as the primary forcing of $\delta J$ on the left-hand side. However, inaccuracies in the gradient coefficients' approximation [Eq. (2)], such as its variation with $t_{g}$, hereinafter the gradient's "target instance," can result in discrepancies between the model's estimate $\delta J$ and its reconstruction. In this study, as

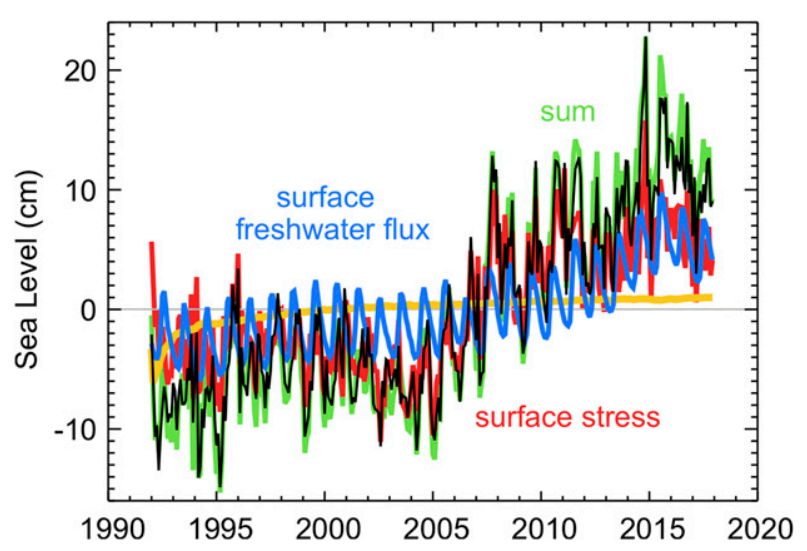

FIG. 5. Monthly mean time series of different controls' contribution to ECCO's Gyre-mean sea level anomaly: surface stress (red), surface freshwater flux (cyan), initial condition (orange), and sum of the three (green). Also shown in black for reference is ECCO's actual sea level as in Fig. 3a. 


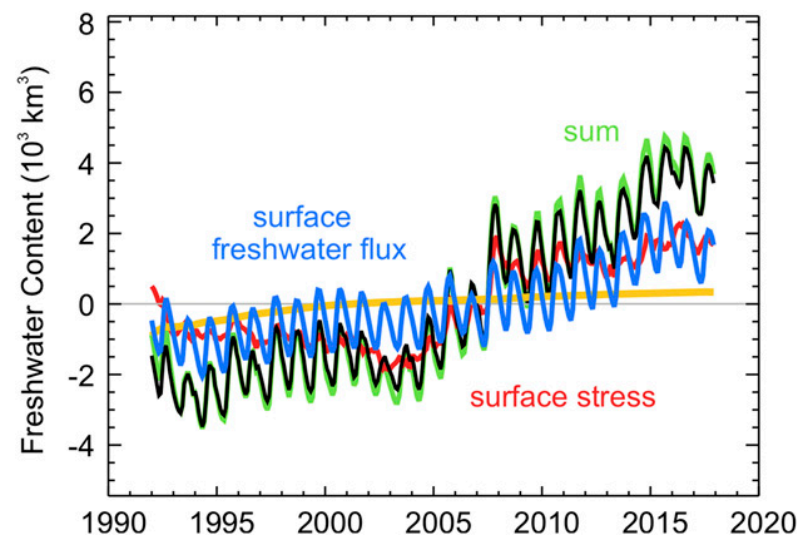

FIG. 6. As in Fig. 5, but for net freshwater content anomaly: The black curve is ECCO's actual net freshwater content as in Fig. 3d.

described in the appendix, we extend the approximation by employing three gradients at different target instances along with additional corrections that account for inaccuracies in the computed gradients. With such rectified approximation, the gradient reconstructions by surface freshwater flux and surface stress are nearly indistinguishable from corresponding model estimates (cf. cyan and black in Figs. A1a and A4 in the appendix), formally explaining $95 \%$ and $82 \%$ of their respective simulations' variance.

Using such approach, Fig. 9 identifies where the Beaufort Sea's variation is forced. Specifically, the figure shows the variance of Gyre-mean sea level explained by different forcings at different locations based on the gradient decomposition. To distinguish seasonal-to-interannual variations from intraseasonal ones, here we focus on Gyre-mean halosteric sea level change (Fig. 3c), namely,

$$
\begin{aligned}
& E_{i}(\mathbf{r}) \equiv \\
& \frac{1}{d S(\mathbf{r})}\left[1-\frac{\operatorname{var}\left\{J_{\text {halosteric }}(t)-\left.\sum_{\Delta t} \frac{\partial J}{\partial \phi_{i}}(\mathbf{r}, \Delta t)\right|_{t_{g}} \delta \phi_{i}(\mathbf{r}, t-\Delta t)\right\}}{\operatorname{var}\left\{J_{\text {halosteric }}(t)\right\}}\right],
\end{aligned}
$$

where $J_{\text {halosteric }}$ represents the Gyre region's mean halosteric sea level, $d S$ is the area of each location, and var \{\} denotes the variance of its argument.

Contributions by surface stress (Fig. 9a) occur mainly along the boundary of the Gyre region instead of the Gyre itself. In particular, the largest surface stress contribution is found along the southern border of the region consistent with Proshutinsky et al. (2019). The general "doughnut shaped" distribution is suggestive of this contribution reflecting lateral Ekman transport of surface intensified freshwater content (Fig. 4) into and out of the Gyre region. Indeed, additional analysis shows that $97 \%$ of the stress-driven variance is explained by surface stress in the direction parallel to the Gyre region's boundary, with little contribution from stress perpendicular to the border.

In contrast to surface stress, contributions by surface freshwater flux (Fig. 9b) occur mainly over the Gyre region itself. Notably, however, the area on the continental shelf south of the Gyre has

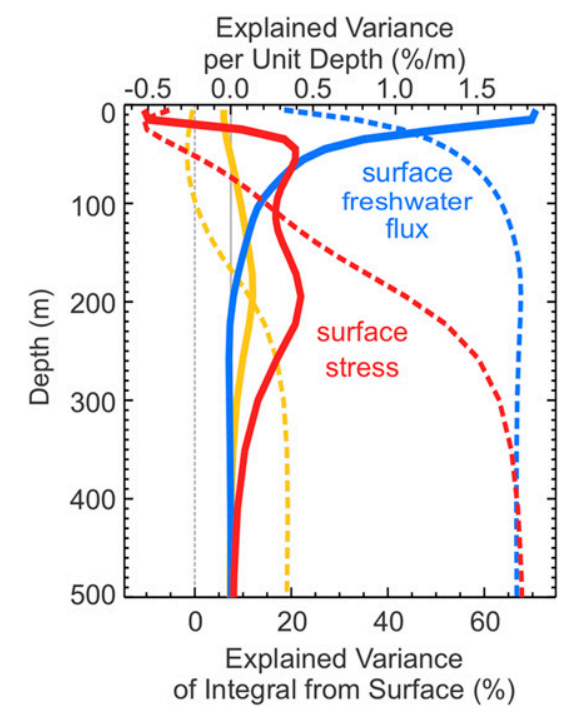

FIG. 7. Vertical variation of the different controls' contribution to the Gyre region's freshwater content change: surface stress (red), surface freshwater flux (cyan), and initial condition (orange). The contributions are shown, as in Fig. 4b, in terms of variance of ECCO's total freshwater content change explained as a function of depth (solid curves, with axis at top) and as an integral from the surface (dashed curves, with axis at bottom).

sizable negative values of explained variance. Negative values imply contributions significantly different from what actually takes place, the nature of which will be examined further below.

In a similar manner, Fig. 10 illustrates the time scale of the causal elements in terms of each component's variance explained by the corresponding control up to different lags $T$,

$$
\begin{aligned}
& E_{i}(0 \leq \Delta t \leq T) \equiv \\
& 1-\frac{\operatorname{var}\left\{J_{i}(t)-\left.\sum_{\mathbf{r}} \sum_{\Delta t=0}^{T} \frac{\partial J}{\partial \phi_{i}}(\mathbf{r}, \Delta t)\right|_{t_{g}} \delta \phi_{i}(\mathbf{r}, t-\Delta t)\right\}}{\operatorname{var}\left\{J_{i}(t)\right\}},
\end{aligned}
$$

where $J_{i}$ denotes the full reconstruction summing over all lags by the particular control $\phi_{i}$. Contributions by surface freshwater flux (cyan) depend on controls over longer lags than do contributions by surface stress (red). For instance, $80 \%$ of the respective contributions' variance is explained by lags up to 236 weeks for freshwater flux but only 19 weeks for surface stress. This temporal disparity can also be evidenced in the time scales of the corresponding model sensitivities (cf. appendix). These differences may be explained by the relative speed of mixing and advection removing a tracer anomaly (surface freshwater flux) from inside the semiclosed circulation of the anticyclonic Beaufort Gyre (Figs. 2b and 9b) being slower than planetary waves, especially topographic and coastally trapped waves, radiating away mechanically driven perturbations (surface stress) near the edge of this region along the continental slope (Fig. 9a). As such, the Gyre region acts as a timeintegrating low-pass filter to surface freshwater flux but has a shorter-term memory of surface stress forcing. This time-scale difference implies that, in the absence of additional forcing, the 


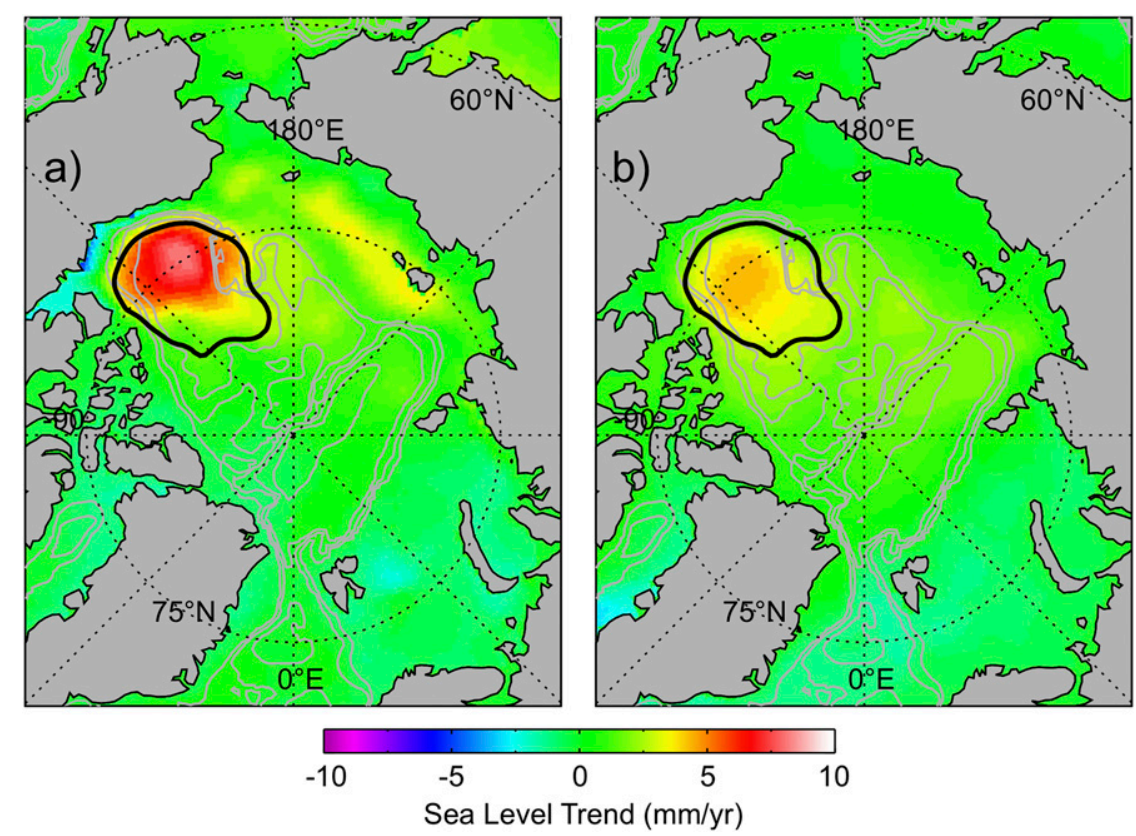

FIG. 8. Sea level trend of ECCO V4r4 from 1993 to 2017 due to anomalies of (a) surface stress and (b) surface freshwater flux. Black and gray curves outline the Gyre region and bathymetry at 1000-m intervals, respectively, as in Fig. 2.

surface-freshwater-flux-driven changes will persist longer (years) than will the surface-stress-driven changes (weeks).

The model's sensitivities to the controls, $\partial J /\left.\partial \phi_{i}(\mathbf{r}, \Delta t)\right|_{t_{g}}$ used in Eq. (1), provide additional insight into the nature of the ocean's response. Figure 11 shows examples of the gradients with respect to surface stress parallel to the Gyre region's boundary in the clockwise direction (Fig. 11a) and to surface freshwater flux into the ocean (Fig. 11b). Consistent with its attribution to Ekman transport, the sensitivity to surface stress is positive and dominant along the Gyre's boundary: sea level rise inside the Gyre region for clockwise stress around its boundary.

In contrast, the sensitivity to surface freshwater input (Fig. 11b) is positive throughout the Gyre region and extends beyond the domain southward through the Bering Strait into the North Pacific Ocean, reflecting mixing and circulation pathways of the ocean. Notably, unlike explained variance (Fig. 9b), the sensitivity to surface freshwater flux has the same sign (positive) on the shelf south of the domain as it does in the Gyre itself, indicating that the negative explained variance in Fig. $9 \mathrm{~b}$ reflects the nature of the forcing rather than that of the ocean. Indeed, on the shelf, freshwater flux into the ocean decreases with time, whereas it increases in the Gyre region (Fig. 12).

Figure 12a compares weekly-mean time series of surface freshwater flux anomalies into the ocean averaged across the Gyre region (red) and over the shelf (cyan) where explained variance in Fig. $9 \mathrm{~b}$ is negative with values less than $-0.75 \times$ $10^{-6} \mathrm{~km}^{-2}$, hereinafter referred to simply as the "Shelf" region. This Shelf region has an area of $98194 \mathrm{~km}^{2}$, which is about one-tenth of that of the Gyre region. While the seasonal cycle is the primary freshwater flux variation in both regions, their magnitudes change differently over time. On the Shelf, freshwater fluxes into the ocean that occur during summer decrease in the latter half of the time series whereas the freshwater fluxes out of the ocean during winter increase, with opposite tendencies found in the Gyre. The discrepancy between the two regions is evidenced more clearly in Fig. 12b in terms of 52-week running means of the flux anomalies, showing decreasing values on the Shelf (cyan) but increasing ones in the Gyre (red), both changing sign around 2007.

The spatial variation of surface stress's contribution (Fig. 9a) and its effect (Fig. 11a) can also be rationalized. For instance, time-mean near-surface freshwater content (Fig. 13a) is nearly uniform along the Gyre region's boundary with slightly elevated values in the southeast quadrant similar to surface stress' sensitivity (Fig. 11a). Standard deviation of along-boundary surface stress is largest at the southern end of the Gyre (Fig. 13b) coincident with the area of maximum contribution (Fig. 9a). Both characteristics are consistent with surface stress's contribution being a reflection of lateral Ekman transport.

\section{c. Summary}

In summary, the analysis reveals lateral freshwater convergence by surface stress-driven Ekman transport and direct freshwater input at the surface are the main processes underlying the ECCO estimate's Beaufort Sea freshwater content change and its associated sea level variation. In the next section we explore the nature of these forcings to discern the relative roles of the atmosphere and sea ice and their interactions with the ocean.

\section{Nature of the forcing}

Sea ice modulates fluxes in and out of the ocean and can also act as a reservoir of freshwater and heat (latent). In fact, 


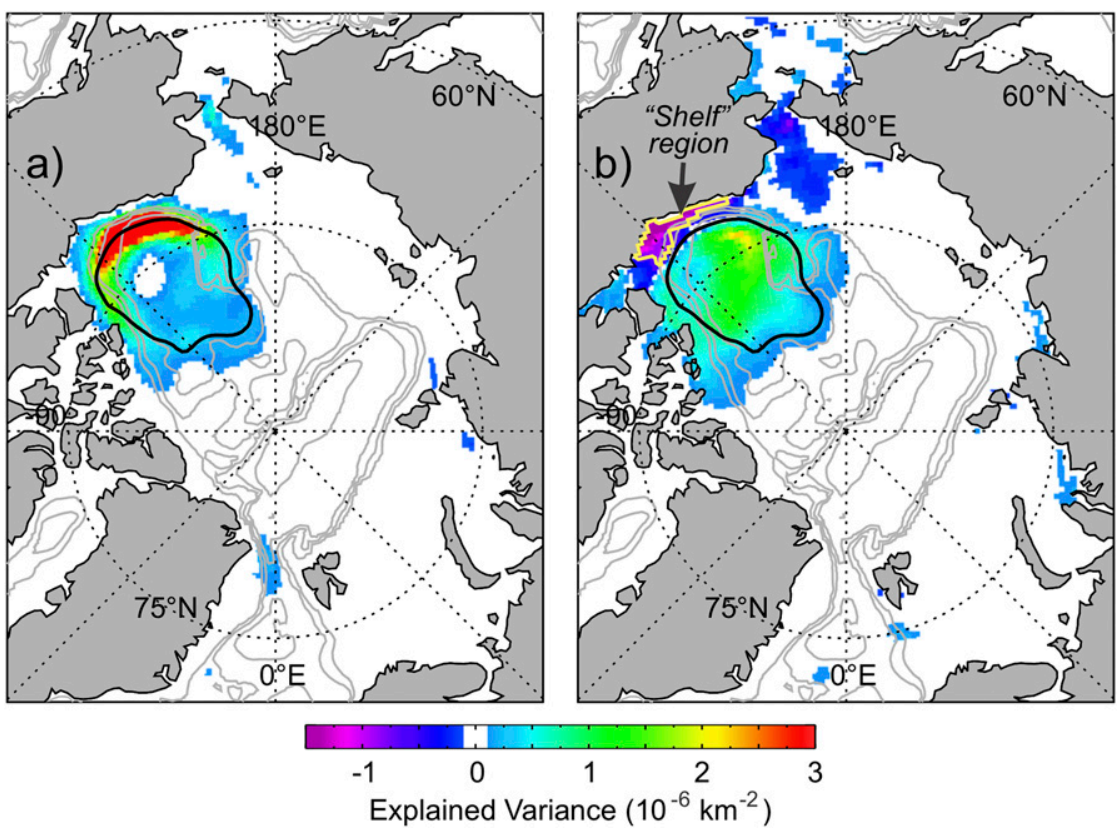

FIG. 9. Location of the forcings responsible for the Gyre region's mean halosteric sea level change (Fig. 3c), in terms of explained variance $\left[10^{-6} \mathrm{~km}^{-2}\right.$; Eq. (3)]: (a) surface stress and (b) surface freshwater flux. Regions with small contribution (magnitudes less than $0.1 \times 10^{-6} \mathrm{~km}^{-2}$ ) are omitted for clarity (whited out). The yellow contour in (b) corresponds to $-0.75 \times 10^{-6} \mathrm{~km}^{-2}$ and outlines the Shelf region analyzed in the study; the region has a latitude and longitude range of $69.1^{\circ}-71.6^{\circ} \mathrm{N}$ and $130.8^{\circ}-152.9^{\circ} \mathrm{W}$, respectively. Black and gray curves outline the Gyre region and bathymetry at 1000-m intervals, respectively, as in Fig. 2.

interannual variation of ocean surface freshwater flux in both the Gyre and Shelf regions examined above in Fig. 12b reflect changes in ocean/sea ice exchange, i.e., sea ice melting and ocean freezing, rather than fluctuations in atmospheric fluxes. Although melting and freezing of sea ice do not affect manometric sea level (Gregory et al. 2019), they can modify steric sea level, in particular, its halosteric component due to the freshness of sea ice relative to the ocean (Noerdlinger and Brower 2007). Here, we investigate mechanisms of the sea ice variation, focusing on drivers of its change and its effect on the ocean.

\section{a. Sea ice variations of the Beaufort Sea}

Figure 14 illustrates the fidelity of ECCO's sea ice estimate in terms of its area across the Gyre and Shelf regions in comparison with satellite observations. ECCO's V4r4 estimation does not directly constrain model sea ice, but does so indirectly using these observations. Specifically, observations of sea ice area are used as pseudo sea surface temperature data whenever sea ice is observed but not simulated by the model, by constraining the estimate's sea surface temperature to be at the freezing point and thus promoting sea ice growth in closer agreement with observations. The model is not constrained, however, in situations where the amount of model sea ice exceeds that of observations. To parameterize unresolved sea ice leads, maximum sea ice concentration in ECCO was limited to $97 \%$, which is reflected as a small bias in Fig. 14a between model and data during winter months.
In both regions, change in ECCO's sea ice area (red and cyan) is dominated by the seasonal cycle modulated by interannual variations during summer months with generally smaller area during the second half of the time series than the first, consistent with corresponding observations (black and orange). During winter, the two regions are covered with sea ice for both model and data, except for the bias described above. Formally, the model explains $85 \%$ and $90 \%$ of the observation's variance, respectively, in the Gyre and Shelf regions.

Interannual variations are more apparent in terms of deviations from respective mean seasonal cycles (Fig. 14b); here, the model explains $70 \%$ and $35 \%$ of the observed interannual variance for the two areas. ECCO's relatively smaller formal skill for the latter Shelf region is due to the model estimate having a somewhat larger variation than what the observation has; the two have a correlation coefficient of 0.78 , with the data formally explaining $59 \%$ of the model's variance. In both regions, despite their differences in oceanice freshwater flux (Fig. 12b), there is less sea ice during summer in the second half of the time series than the first with the change occurring around 2007.

\section{b. Mass and heat budgets}

Property budgets further elucidate the contrasting characters of the different periods and regions. Figure 15 compares time-integrated convergence of different components of ECCO's sea ice mass budget, the sum of which corresponds to sea ice 


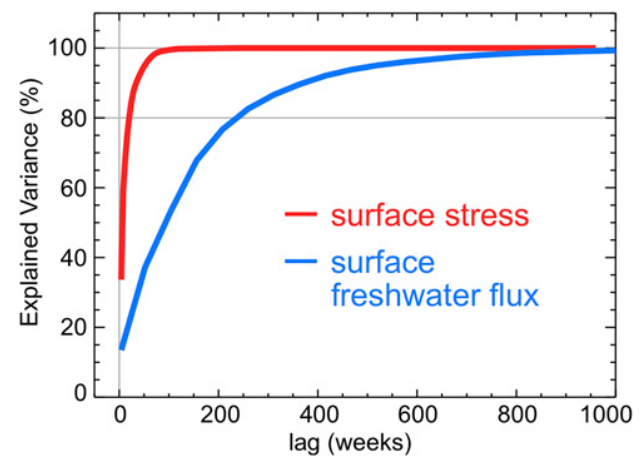

FIG. 10. Time scale of the forcings' contribution to the Gyre region's mean sea level variation, shown in terms of self-explained variance up to different lags $T$ [Eq. (4)]: surface stress (red) and surface freshwater flux (cyan).

mass itself (black and its scaled version in gray). In both the Gyre (Fig. 15a) and the Shelf regions (Fig. 15b), there is a dominant balance between fluxes associated with melting and freezing (red) and horizontal advection (cyan), which account for most of sea ice's seasonal-to-interannual change. Precipitation (orange) in comparison has negligible temporal variation and smaller contribution to the overall budget. The two regions, however, differ in the sense of the overall balance. That is, on average, sea ice converges and melts in the Gyre region but on the Shelf the ocean freezes and the resulting ice diverges away. Notably, in both regions, the rate of these convergence and divergence (general slope of the curves) increase significantly after 2007.

The heat source/sink responsible for the sea ice melt/freeze (red in Fig. 15) can be assessed from the heat budget of sea ice. Figure 16 compares sea ice's time-integrated heat flux divergence to the ocean (cyan) and atmosphere (black) in ECCO, the sum of which equals the latent heat of sea ice freezing and melting (red). Temporal change in the curves' overall slope indicates that, in the Gyre region, the ocean (cyan in Fig. 16a) becoming a heat source after 2007 is the primary cause of the rapid increase in the region's sea ice melt (red). In comparison, for the Shelf region (Fig. 16b), both the ocean (cyan) and the atmosphere (black) contribute equally as heat sinks in the increasing formation of sea ice (red) after 2007.

The origin and fate of heat associated with these ocean-ice interactions (cyan in Fig. 16) can in turn be ascertained from the ocean's heat budget. Figure 17 shows ECCO's timeintegrated heat flux convergence integrated over the top $80 \mathrm{~m}$ of the ocean for the two separate regions. In both, the nearsurface ocean heat content (black and its scaled version in gray) increases over time, especially during summer, but its temporal variation is much smaller than those of the separate fluxes that make up the budget (Timmermans et al. 2018). Specifically, in the Gyre region (Fig. 17a), change in overall slope signify that the increasing heat loss to sea ice (cyan) after 2007 is balanced by a corresponding increase in heat convergence from horizontal advection (red) and, somewhat later, the atmosphere (magenta); i.e., the increasing heat going into sea
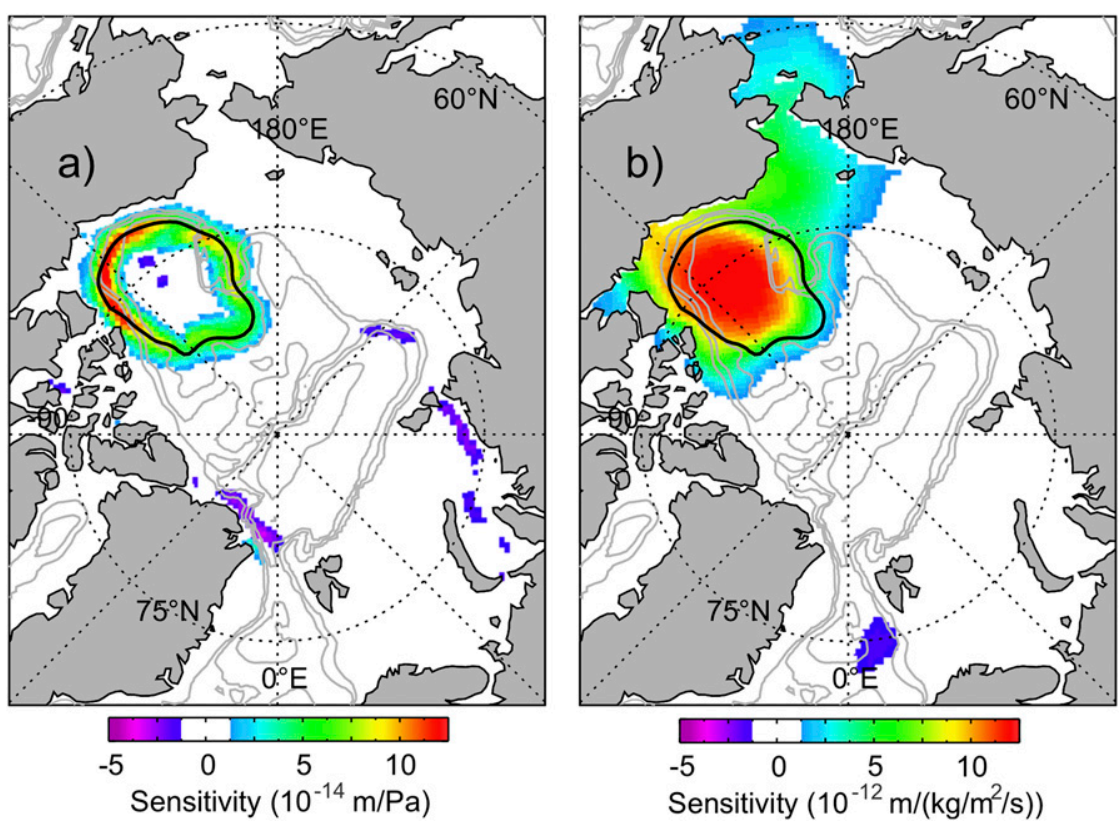

FIG. 11. Sensitivity of the Gyre-mean sea level to 1-week-long forcing perturbations at different locations: (a) clockwise along-boundary surface stress at 8-weeks lag and (b) surface freshwater flux input at 78-weeks lag. Both are at lags close to their respective instances of maximum contribution (maximum slope in Fig. 10). The sensitivities are for $t_{g}=$ December 2017 [Eq. (2)]. For clarity, values

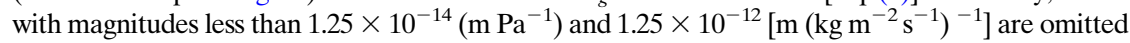
(whited out) in (a) and (b), respectively. Black and gray curves outline the Gyre region and bathymetry at 1000-m intervals, respectively, as in Fig. 2. 

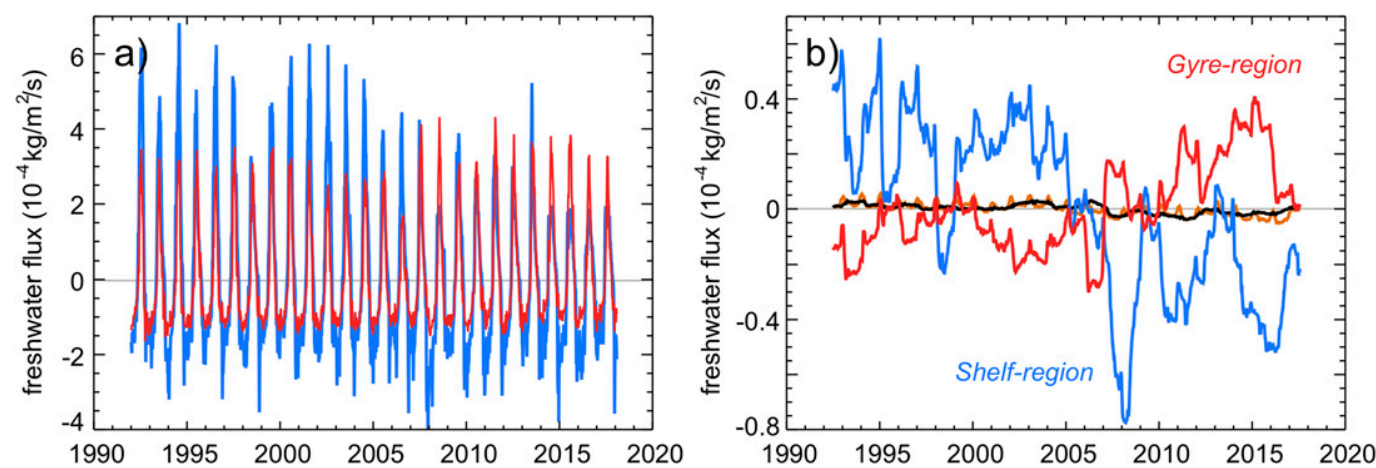

FIG. 12. (a) Weekly-mean time series of surface freshwater flux anomaly $\left(10^{-4} \mathrm{~kg} \mathrm{~m}^{-2} \mathrm{~s}^{-1}\right)$, and (b) its 52-week running mean averaged across the Gyre (red) and Shelf regions (cyan). Flux into the ocean is shown as positive. The Shelf region is defined in Fig. 9b. Also shown in (b) for reference are the 52-week running means of atmospheric freshwater flux anomalies averaged across the Gyre (black) and Shelf regions (orange). Gray lines in (a) and (b) indicate zero.

ice melt is advected in from the surrounding area and gained from the atmosphere. Formally, advection and atmosphere account for $64 \%$ and $50 \%$, respectively, of the change in oceanice heat flux. Further analysis shows that the atmospheric component reflects the ocean's increased absorption of shortwave radiation resulting from the region's decrease in sea ice cover (Fig. 14). Together, the change in the Gyre region is suggestive of a positive feedback in sea ice melt; that is, increasing heat flux from lateral convergence (red) reduces sea ice cover (cyan), enhancing the ocean's solar heat absorption (magenta) that additionally contributes to sea ice melt (cyan).

In comparison, on the Shelf (Fig. 17b), the increasing heat gain from sea ice production (cyan) after 2007, along with that from the atmosphere (magenta), is exported by horizontal advection (red) and mixing (pink), which is also primarily horizontal. Additionally, on the Shelf (Fig. 17b), the seasonal cycle of atmospheric heat flux (magenta) causes a seasonal variation of ocean heat content (black), whereas in the Gyre (Fig. 17a), the former primarily drives a seasonal modulation of ocean-to-ice heat flux (cyan). This difference can be attributed to the Shelf region becoming ice-free in summer in contrast to the Gyre region retaining ice (Fig. 14a); namely, sea ice with its latent heat acts as a thermostat, regulating temperature and heat content change in the ocean. In fact, as the amount of summer sea ice decreases in the latter half of the time series, this "thermostat effect" diminishes and the seasonal cycle of
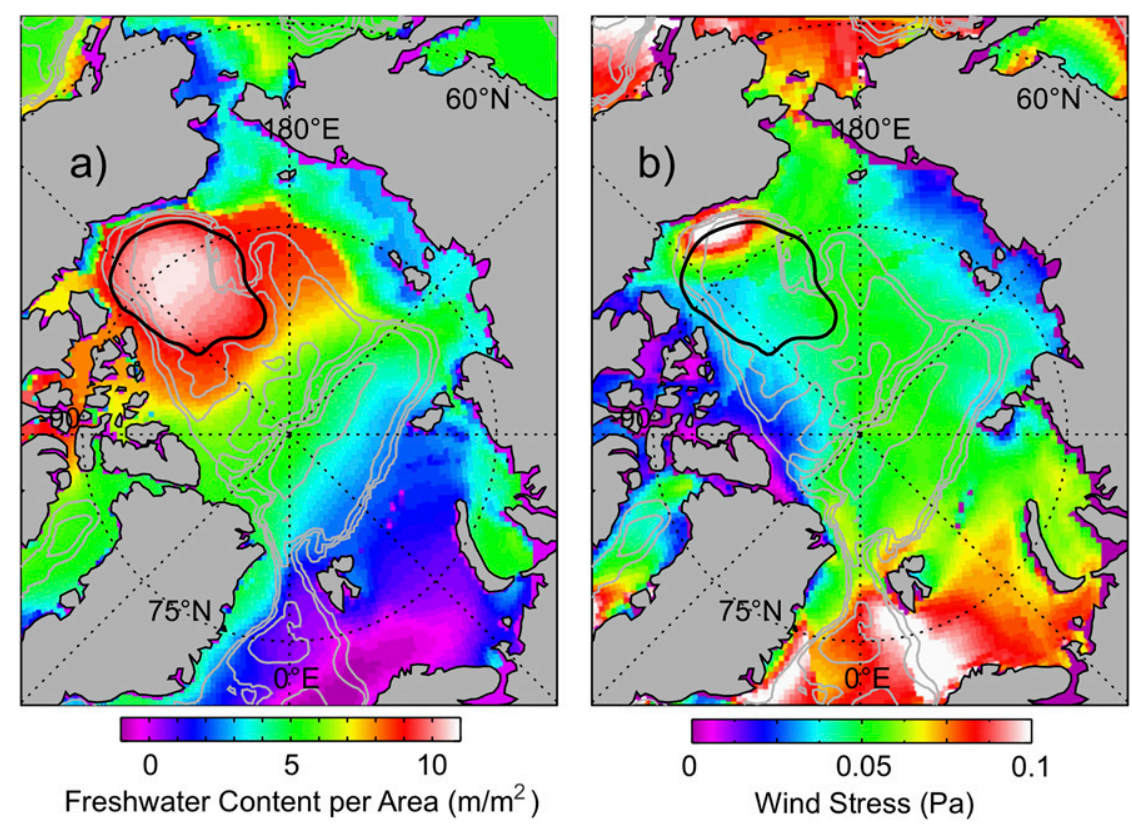

FIG. 13. (a) Time-mean freshwater content per unit area integrated from the surface to $100-\mathrm{m}$ depth or the ocean floor, whichever is shallower, and (b) standard deviation of wind stress parallel to the boundary of the Gyre region. Black and gray curves outline the Gyre region and bathymetry at 1000-m intervals, respectively, as in Fig. 2. 

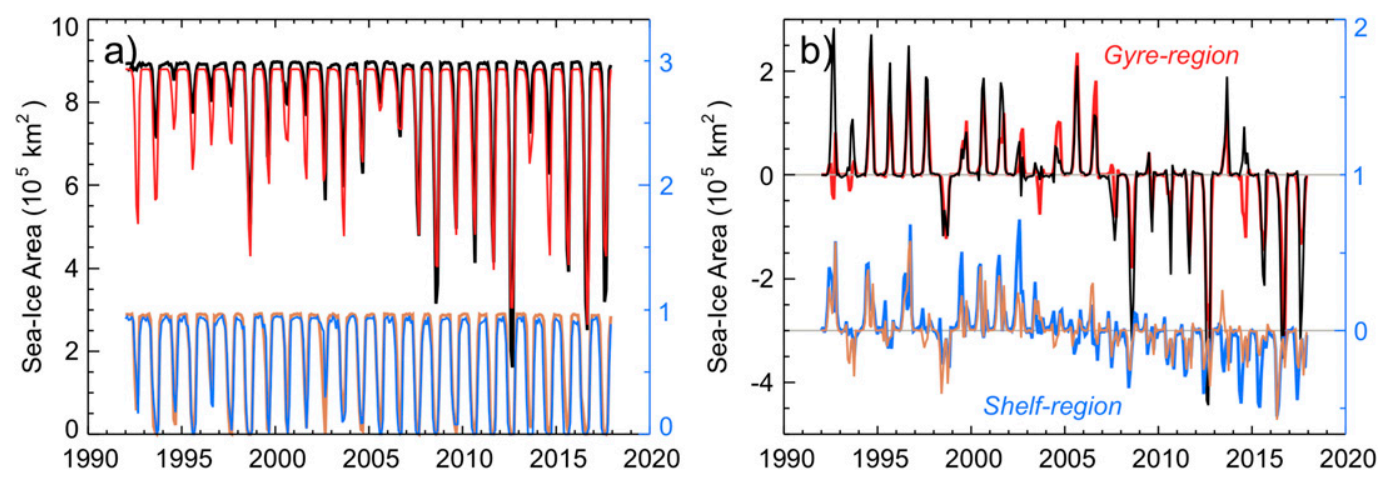

FIG. 14. (a) Monthly-mean time series (ECCO and data) of sea ice area $\left(10^{5} \mathrm{~km}^{2}\right)$, and (b) deviations from their mean seasonal cycle, averaged across the Gyre (red and black) and Shelf regions (cyan and orange), respectively. Values for the Shelf region are enlarged [and also offset in (b)] for clarity, with values given on the cyan axis to the right.

ocean heat content (black and gray) becomes larger in both regions. Last, for both Gyre and Shelf regions, the ocean is as large a heat source/sink for seasonal sea ice melt as direct atmospheric forcing is (Fig. 16), even though, needless to say, atmospheric forcing is the source/sink for seasonal ocean warming/cooling itself (Fig. 17).

In conclusion, the ECCO estimate shows that Beaufort Sea's interannual-to-decadal sea ice variation reflects a wind-driven diabatic change of the combined ocean and sea ice system. In the Gyre, strengthening wind-driven convergence brings extra sea ice into the region of climatological sea ice melt. The convergence also transports extra heat within the ocean that increases this melt, which in turn intensifies shortwave ocean-warming that further accelerates the melt. On the Shelf, change in wind stress increases divergence of sea ice away from the region, exposing the ocean to the atmosphere allowing even more sea ice to form and to be exported out to the Gyre to melt.

\section{c. Wind-driven diabatic change}

The wind-driven diabatic change mechanism deduced in the previous section can be tested numerically with the ECCO estimate's coupled ocean and sea ice model. A flux-forced version of the coupled model is employed using the same atmospheric fluxes as in the ECCO estimate but replacing wind stress with its time-mean. This experiment is similar to that described in section 4a except instead of a stand-alone ocean model, the model here is a coupled ocean-sea ice model with ocean-ice exchange being state dependent.

Indeed, this flux-forced coupled model lacks most of the Gyre region's interannual variation found in ECCO. Figure 18 shows time series of Gyre-mean sea level from this flux-forced coupled model (red) in comparison with that from ECCO (black) and contributions solely from ECCO's surface freshwater flux to the ocean (cyan). The flux-forced coupled model (red) lacks the wind-driven subannual-to-interannual variation of ECCO (black), but does have the same annual cycle as its surface freshwater flux contribution (cyan) since the annual cycle is driven by atmospheric diabatic forcing that the flux-forced coupled model retains. Importantly, however, this flux-forced coupled model (red) lacks most of the interannual variation of ECCO's surface freshwater flux contribution (cyan), consistent with the wind-driven diabatic change mechanism above;
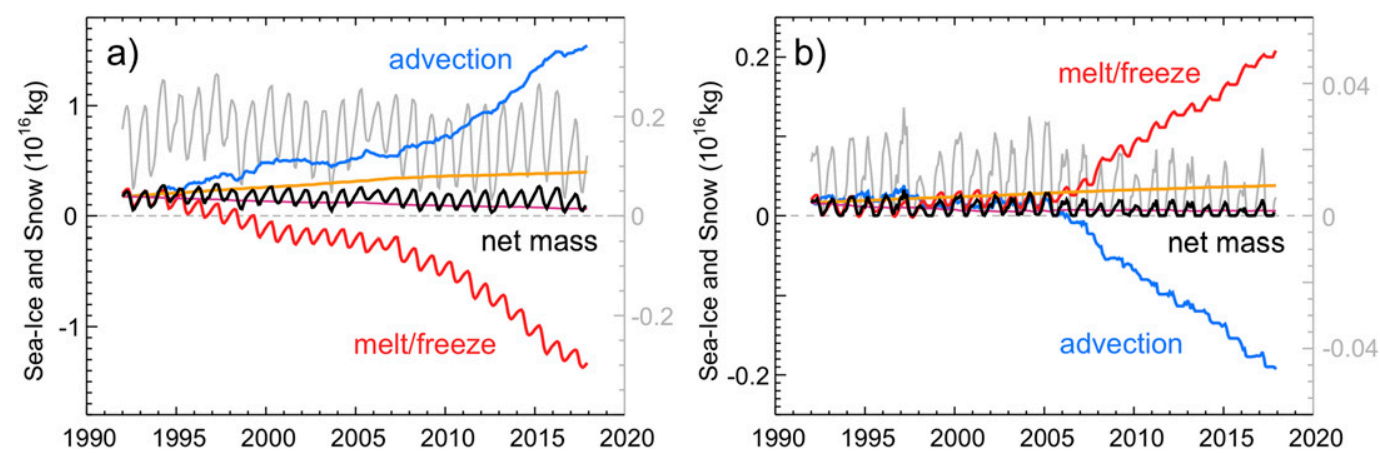

FIG. 15. Sea ice mass budget, showing time- and horizontally integrated mass flux convergence of sea ice $\left(10^{16} \mathrm{~kg}\right)$ across (a) the Gyre and (b) the Shelf for advection (cyan), melt/freeze exchange with the ocean (red), and exchange with the atmosphere (orange). The sum of other fluxes, such as nonmelt exchange with the ocean, is shown in magenta. Negative slopes indicate divergence from sea ice. The sum of these integrated fluxes (black) corresponds to net sea ice mass (also scaled for clarity in gray, with the axis on the right). Gray dashed lines indicate zero. 

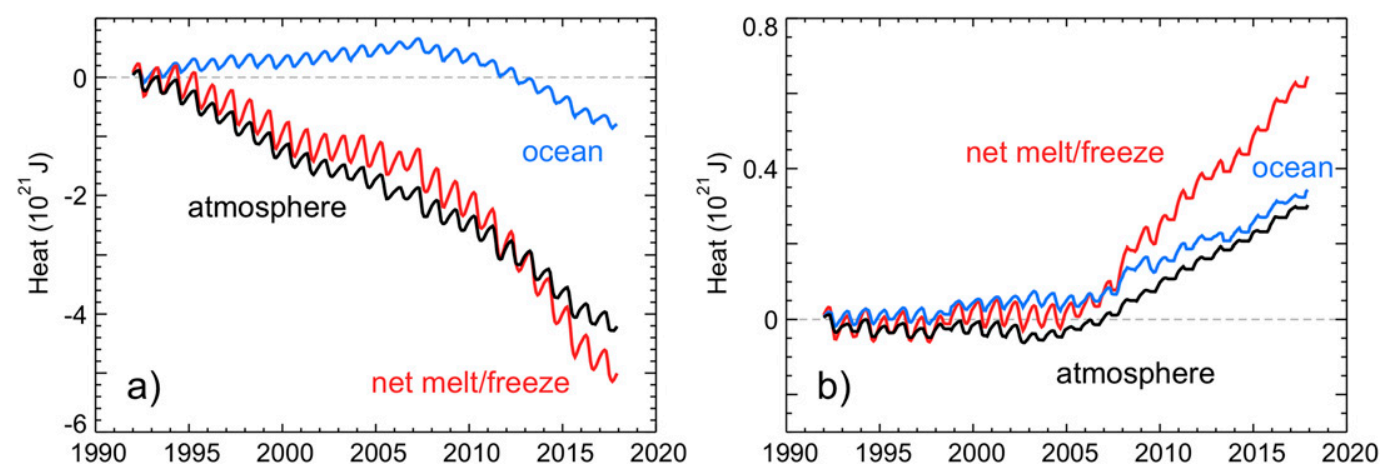

FIG. 16. Sea ice heat budget, showing time- and horizontally integrated heat flux divergence from sea ice $\left(10^{21} \mathrm{~J}\right)$ across (a) the Gyre and (b) the Shelf for ocean exchange (cyan) and atmosphere exchange (turbulent and radiative fluxes; black). The sum (red) corresponds to latent heat associated with the melting and freezing of sea ice shown as the red line in Fig. 15. Heat divergence (positive slope) corresponds to freezing sea ice. Negative slopes indicate heat convergence and melt. Gray dashed lines indicate zero.

The change in trend before and after 2007 of the former (red) is $35 \%$ of that of the latter (cyan), comparable to the relative magnitude of radiative warming contributing to ECCO's sea ice melt retained in the flux-forced coupled model (Fig. 17a).

\section{d. Effect of sea ice on surface stress}

Sea ice, in addition to diabatic fluxes examined in the previous section, can also modulate momentum flux between the ocean and the atmosphere. Here we explore the effect of changing sea ice cover on ocean surface stress and its influence on Beaufort Sea's variation.

Figure 19 examines the difference between ECCO's stress at the bottom of the atmosphere (wind stress) and that at the liquid surface of the ocean (ocean stress) in terms of Ekman pumping (positive upward) averaged across the Gyre region. Their difference (former minus latter in red) is negligible during summer when sea ice concentration is at its minimum but can be sizable during winter when the region is covered by sea ice (Fig. 14). The magnitude of this wintertime difference increases over the decades, despite the declining sea ice cover, because of the increasing magnitude of wind stress itself (cyan).
That is, ECCO's changing ocean stress is mostly a reflection of changing wind stress, and the effect of sea ice cover on ocean surface stress (e.g., Meneghello et al. 2018) is of secondary importance to the Beaufort Sea's variation. In contrast to surface freshwater flux (Fig. 12a), Fig. 19 also illustrates how seasonal variation of ocean stress is negligible in comparison with other variations, which explains the relatively small seasonal component in the Gyre's surface stress-driven change (Fig. 6).

Finally, the change in wind stress estimated by ECCO is notably larger than that of ERA-Interim (gray in Fig. 19). Time-mean Ekman pumping before and after 2007 are -8.1 and $-23.2 \mathrm{~cm} \mathrm{day}^{-1}$ for ECCO and -8.1 and $-10.4 \mathrm{~cm} \mathrm{day}^{-1}$ for ERA-Interim, respectively, accounting for sea ice cover in the former pair but not in the latter. Although the change before and after 2007 of ERA-Interim stress is correlated with that of sea level, given sea level's magnitude of change relative to its mean (Fig. 2), the fractional change in ERA-Interim's wind stress is too small to explain the observed sea level variation (see also Giles et al. 2012; Regan et al. 2019). In fact, from 1996 to 2010, Giles et al. (2012) finds an almost threefold increase in Beaufort Sea's surface geostrophic velocity, which
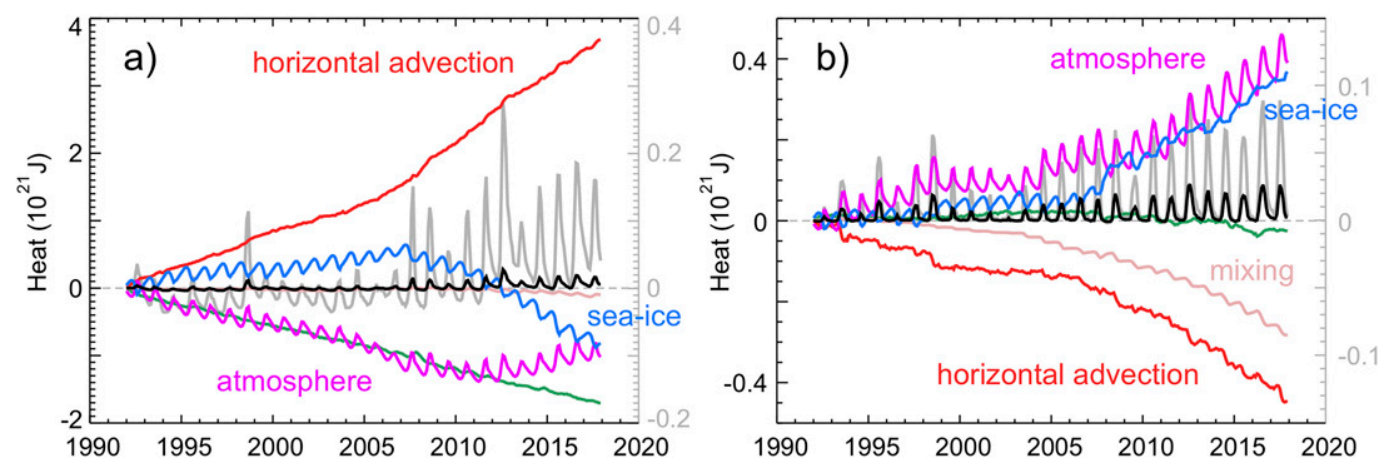

FIG. 17. Ocean heat budget, showing time- and spatially integrated heat flux convergence over the top $80 \mathrm{~m}$ of the ocean $\left(10^{21} \mathrm{~J}\right)$ across (a) the Gyre and (b) the Shelf for sea ice exchange (cyan), atmospheric exchange (turbulent and radiative fluxes; magenta), horizontal advection (red), vertical advection (green), and mixing (pink). Negative slopes indicate divergence, i.e., ocean cooling. The sum of these fluxes (black) corresponds to ocean heat content (also scaled for clarity in gray, with the axis on the right). Gray dashed lines indicate zero. 


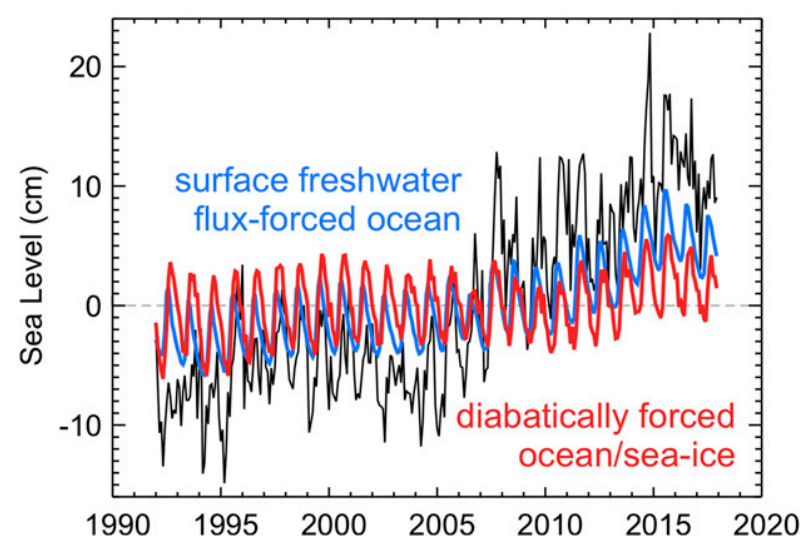

FIG. 18. Monthly mean time series of sea level anomaly averaged across the Gyre region for the atmospheric flux-forced coupled ocean and sea ice model with time-invariant wind stress (red), ocean surface freshwater flux contribution to ECCO (cyan), and ECCO (black). The latter two are the same as in Fig. 5.

largely reflects wind-driven change (section 4a), consistent with the present estimate. Additionally, Spreen et al. (2011), based on satellite observations between 1992 and 2009, identifies a rapid increase in the speed of sea ice drift after 2004 that cannot be explained by atmospheric reanalyses, lending support to the reanalyses' possible underestimation of the region's surface wind stress change. Further assessment of the stress, and other aspects of the ECCO estimate, calls for analysis of additional observations and is left for future investigation.

\section{Summary and conclusions}

Using the latest ocean and sea ice state estimate and modeling system of the Consortium for Estimating the Circulation and Climate of the Ocean (ECCO), version 4, release 4 (V4r4), the present study investigates the nature and causal mechanism of sea level change and freshwater content variation across the Arctic's Beaufort Sea from 1992 to 2017. Aside from a largely subannual barotropic oscillation that is part of a remote-windforced fluctuation spanning the interconnected deep Arctic basins (Fukumori et al. 2015), Beaufort Sea's sea level change is almost entirely halosteric reflecting the region's freshwater content evolving on seasonal-to-decadal time scales.

Seasonal variation is dominantly driven by the region's annual melting and freezing of sea ice that modulates freshwater content of the upper $55 \mathrm{~m}$ of the water column. Interannual change is mostly wind-driven, associated with horizontal convergence and vertical pumping (Ekman transport) of water exchanged between the Beaufort Sea and its surrounding area, modifying the region's freshwater content nearly uniformly down to 200-m depth.

At decadal time scales, however, sea ice melt becomes as important as ocean's wind-driven transport. On average, prevailing winds in the Beaufort Sea drive Ekman transport that sets up the Beaufort Gyre where sea ice converges and melts. After 2007, strengthening anticyclonic wind stress enhances not only these transports but also the melt itself. Enhanced ocean Ekman transport increases heat convergence that melts

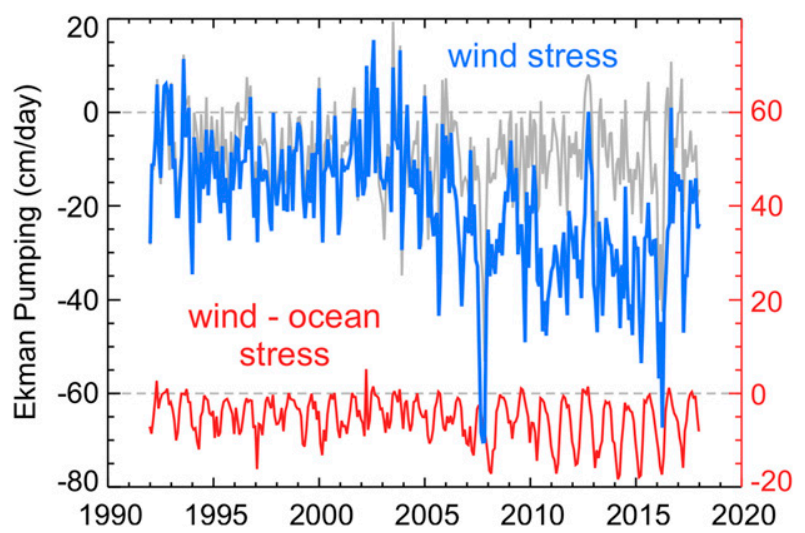

FIG. 19. Monthly mean time series of Ekman pumping $\left(\mathrm{cm} \mathrm{day}^{-1}\right)$ averaged across the Gyre region based on different stress: wind stress (cyan) and wind minus ocean stress difference (red). The difference (red) is offset for clarity, with its axis on the right. Gray is wind stress based on the ERA-Interim reanalysis (Dee et al. 2011). Gray dashed lines indicate zero.

the extra-advected ice and reduces sea ice area, causing the ocean to absorb more shortwave radiation that further increases the melt. The enhanced significance at these longer time scales of sea ice melt relative to direct wind forcing can be ascribed to the ocean's diabatic adjustment to meltwater added inside the semiclosed Beaufort Gyre being slower than its dynamic adjustment to mechanical perturbations near the Gyre's edge. As a consequence, in contrast to wind forcing, the effect of meltwater accumulates over time. This difference implies that, in the absence of additional forcing, sea level and freshwater content change caused by sea ice melt will persist longer than those caused by direct wind-driven ocean circulation change.

Beaufort Sea's decadal variation of sea level and freshwater content amounts to a wind-driven coupled diabatic interaction between the ocean and sea ice. In it, sea ice serves as an extraocean conduit transporting freshwater to the Beaufort Sea from its neighboring regions. In contrast to freezing and melting that occur in place, the growing discrepancy between where sea ice forms and where it melts - in particular, the shelf and deep basin, respectively - effectively doubles the amount of sea level and freshwater content rise resulting from the ocean's response to direct wind forcing alone.

Acknowledgments. This work was carried out at the Jet Propulsion Laboratory, California Institute of Technology, under a contract with the National Aeronautics and Space Administration (NASA).

Data availability statement. Arctic dynamic topography data were provided by the Centre for Polar Observation and Modelling, University College London (http://www.cpom.ucl.ac.uk/dynamic_ topography) (Armitage et al. 2016). The Ice-Tethered Profiler data were collected and made available by the Ice-Tethered Profiler Program (Toole et al. 2011; Krishfield et al. 2008) based at the Woods Hole Oceanographic Institution (https:// www.whoi.edu/itp). The ECCO state estimate is available from NASA's Physical Oceanography Distributed Active 

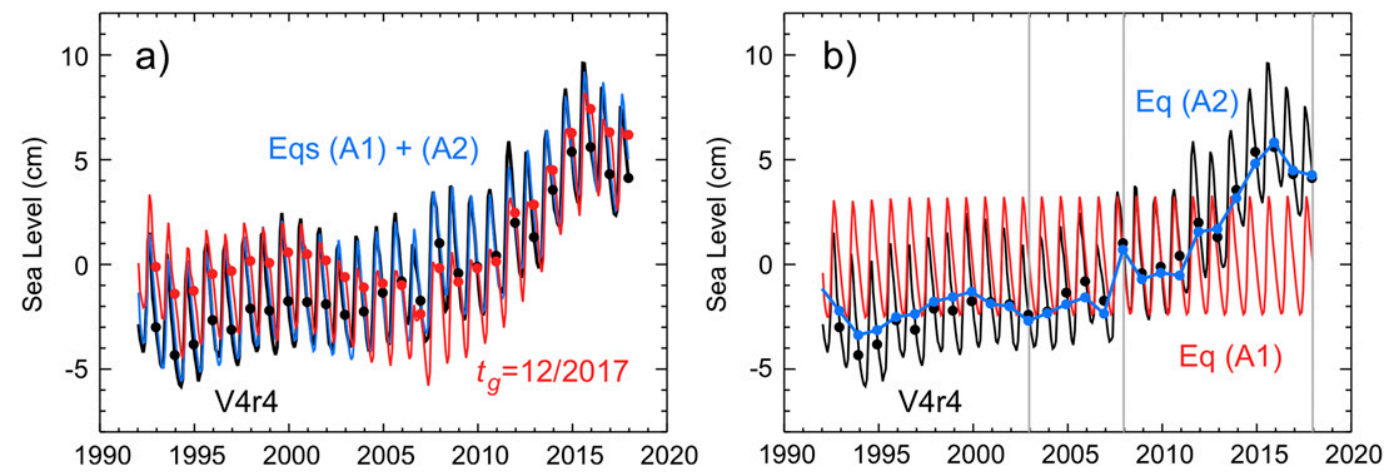

FIG. A1. Adjoint gradient reconstruction (color) of ECCO's surface freshwater-flux-driven Gyre mean sea level anomaly (cm) (black; same as cyan in Fig. 5): (a) Red is reconstruction by the surface freshwater flux component of Eq. (1) (right-hand side) using the gradient at target instance December 2017 and cyan is the modified reconstruction described in (b). (b) Red is the seasonal reconstruction [Eq. (A1)] and cyan is the interannual reconstruction [Eq. (A2)], the sum of which is cyan in (a). Gray vertical lines in (b) denote target instances of the three gradients employed in the interannual reconstruction: Decembers 2002, 2007, and 2017. In (a) and (b), circles mark yearly December values of the corresponding estimates of the same color. [Symbols for cyan in (a) and red in (b) are omitted for clarity].

Archive Center (https://podaac.jpl.nasa.gov/ECCO). The ECCO model can be obtained from the MITgcm code repository on GitHub [https://github.com/MITgcm/MITgcm.git (https://www.eccogroup.org/products-ECCO-V4r4.htm)].

\section{APPENDIX}

\section{Expansion with Rectified Adjoint Gradients}

Inaccuracies in the gradient coefficient can undermine the fidelity of Eq. (1)'s expansion. Here we illustrate examples of such errors and advance approaches to correct them in analyzing Beaufort Sea's variation.

Figure A1a compares ECCO V4r4's sea level anomaly averaged across the Gyre region due to surface freshwater flux (black) and its adjoint gradient reconstruction (red) with $t_{g}=$ December 2017 [Eq. (1)] based on the adjoint of V4r4's fluxforced ocean model (section 2). The reconstruction resolves $70 \%$ of ECCO's variance, but differences are evident at both annual and interannual time scales. To gain insight into the nature of these discrepancies, Fig. A2a compares corresponding adjoint gradients at a particular location in the middle of the Beaufort Sea for different target instances $t_{g}$ (different colors) that this reconstruction diverges from the model. Also shown for reference is the model's forward gradient (black); i.e., the model's Gyre-mean sea level anomaly resulting from a unit perturbation in surface freshwater flux at this same location. Comparison between the adjoint and forward gradients, known as "gradient check," demonstrates consistency between the sensitivities with no systematic disagreement, thus establishing the first-order accuracy of the adjoint model and its results.

The gradients generally decay with lag with a relatively long $e$-folding period of approximately 40 months, likely reflecting the semiclosed nature of the Beaufort Gyre circulation. Yet, some differences are evident, such as the somewhat shorter decay scale for $t_{g}=$ December 2002 (magenta in Fig. A2a) relative to that for 2007 (orange). Differences in subannual variations are also present. For instance, plotting the gradients as functions of actual time, Fig. A2b shows subannual variations being much larger for $t_{g}=$ December for 2017 (red) and 2015 (cyan) than for 2002 (magenta), possibly due to the region's changing sea ice cover (Fig. 14). Moreover, these subannual modulations are dependent on certain periods of the year instead of lag, as evidenced in Fig. A2b's inset by the alignment in time of these modulations and the lack thereof in Fig. A2a.

Taking these gradient variations into consideration can significantly reduce inaccuracies in the reconstruction. Here, noting sea level's distinct time scales in Fig. A1a, we expand its seasonal and interannual variations separately (Fig. A1b) and combine them afterward. Recognizing that the seasonal cycle is a primary variation for surface freshwater flux (Fig. 12a) whereas subannual modulations are secondary for the gradient (Fig. A2b), we reconstruct a representative seasonal cycle $\left(\left\langle\delta J_{\mathrm{FW}}\right\rangle_{\text {seasonal }}\right)$ by employing a particular gradient low-pass filtered in lag ( $\overline{\partial J / \partial \phi_{\mathrm{FW}}}$ low_pass_ $\left.\Delta t\right)$ in combination with the mean seasonal cycle of the freshwater flux $\left(\left\langle\delta \phi_{\mathrm{FW}}\right\rangle_{\text {seasonal }}\right)$, namely,

$$
\begin{aligned}
& \left\langle\delta J_{\mathrm{FW}}\right\rangle_{\text {seasonal }}(t) \\
& \quad \equiv \sum_{\mathbf{r}} \sum_{\Delta t} \frac{\partial J}{\left.\frac{\partial J}{\partial \phi_{\mathrm{FW}}}(\mathbf{r}, \Delta t)\right|_{t_{g}} ^{\text {low_pass_ } \Delta t}}\left\langle\delta \phi_{\mathrm{FW}}\right\rangle_{\text {seasonal }}(\mathbf{r}, t-\Delta t)
\end{aligned}
$$

Here the angle brackets with subscript "seasonal" and overbar with superscript "low_pass_ $\Delta t$ " signify seasonal cycle and lowpass filter in lag $\Delta t$, respectively. Subscript FW indicates variables pertaining to surface freshwater flux. Specifically, we employ the gradient at $t_{g}=$ December 2017 and utilize a 2-yr running mean (Fig. A2b) as its low-pass filter in Eq. (A1), the result of which is shown in red in Fig. A1b.

We reconstruct the interannual variation by deriving yearly December estimates and then linearly interpolating them in 

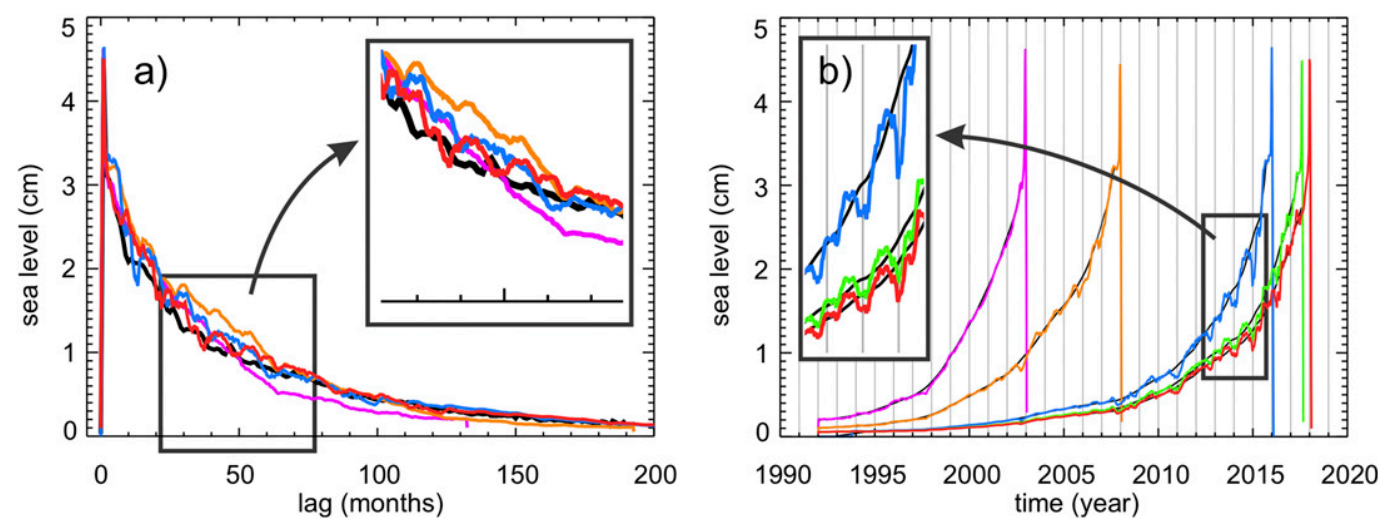

FIG. A2. Adjoint gradient (sensitivity) of Gyre-mean sea level $(\mathrm{cm})$ to a unit 1-week-duration surface freshwater flux perturbation into the ocean $\left(\mathrm{kg} \mathrm{m}^{-2} \mathrm{~s}^{-1}\right)$ near the center of the Gyre region at $73.5^{\circ} \mathrm{N}, 151.8^{\circ} \mathrm{W}$, where contribution of this control is among the largest (Fig. 9b). Shown is the gradient as a function of (a) lag and (b) actual time. Different colored curves correspond to different December target instances: 2002 (magenta), 2007 (orange), 2015 (cyan), and 2017 (red). The gradient for target instance July 2017 (green) is also shown in (b). For comparison, shown in black in (a) is the model's forward gradient to a corresponding perturbation in December 2002. Black curves in (b) are 2-yr running means of the respective gradients, deviations from which illustrate subannual modulations. Gray vertical lines in (b) denote beginning of the year at yearly intervals. Inset diagrams show enlarged portions of the plots for clarity.

between (blue circles and line segments, respectively, in Fig. A1b). Each December estimate is obtained using a gradient interpolated in target instance among a reference set of three gradients with $t_{g}=$ December in 2002, 2007, and 2017. Using the same month of the year for both estimate and gradient in this manner minimizes inaccuracies associated with the seasonal cycle. December estimates prior to 2002 all employ the gradient at $t_{g}=$ December 2002. The December estimate for each year is thus obtained by

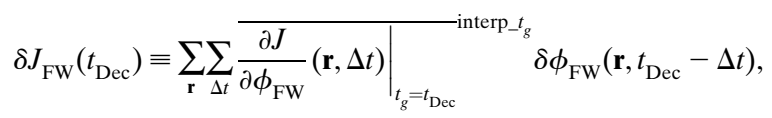

where $t_{\text {Dec }}$ is a particular December and the overbar with superscript "interp_ $t_{g}$ " signifies the interpolation in target instance. Combining Eq. (A1) with linearly interpolated estimates from Eq. (A2) yields the modified reconstruction in Fig. A1a (cyan) that explains 95\% of ECCO's variance of the corresponding sea level change (black).

For surface stress, the gradient's dependence on target instance is not as significant an issue as it is for surface freshwater flux. However, an assessment of the gradient demonstrates possible inaccuracies in ECCO V4r4's adjoint model itself that require attention. For instance, gradients with respect to zonal surface stress near the southern edge of the Gyre region (Fig. A3) have an $e$-folding time scale of less than 2 months, which is notably shorter than that for surface freshwater flux, possibly reflecting faster planetary wave dynamics in response to surface stress perturbation in this region. Importantly, however, for lags beyond a few months, small as they are, the adjoint gradients (color) have much larger values than does a corresponding forward gradient shown in black. In fact, beyond 15 months, the computed adjoint gradients are systematically an order of magnitude larger than the model's forward sensitivity (see Fig. A3 inset).

The adjoint gradient's systematic error can result in inaccuracies in the reconstruction as illustrated in Fig. A4. A

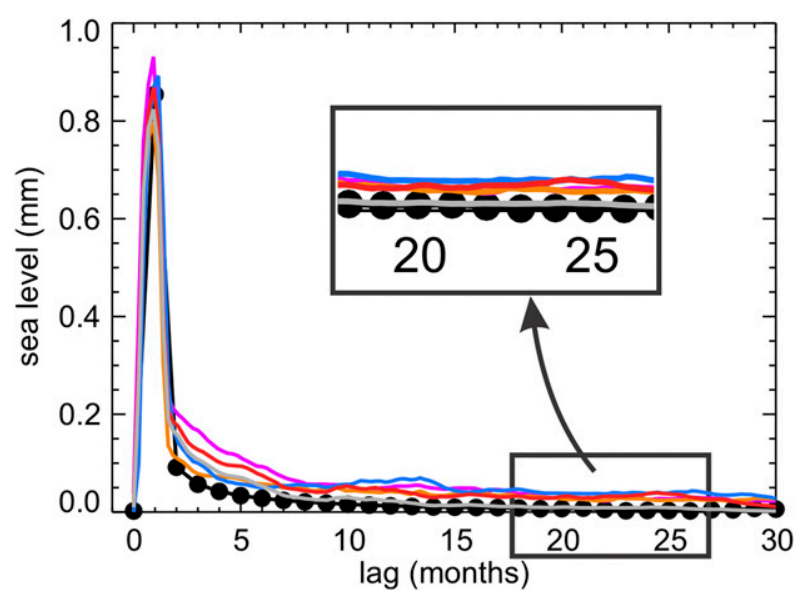

FIG. A3. As in Fig.. A2a, but for zonal surface stress, showing the adjoint gradient of Gyre-mean sea level $(\mathrm{mm})$ to a unit 1-weekduration westward surface stress perturbation $\left(\mathrm{N} \mathrm{m}^{-2}\right)$ near the southern edge of the Gyre region at $72.3^{\circ} \mathrm{N}, 147.8^{\circ} \mathrm{W}$, where contribution of this control is among the largest (Fig. 9a). Shown is the sensitivity as a function of lag. Different colored curves correspond to different December target instances: 2002 (magenta), 2007 (orange), 2015 (cyan), and 2017 (red). The gray curve is the same as the red one but with a 76-week exponential damping applied. Also shown in black (and symbols at monthly intervals) is the model's forward gradient to a corresponding perturbation in December 2002. The inset diagram shows an enlarged portion of the plot for clarity. 


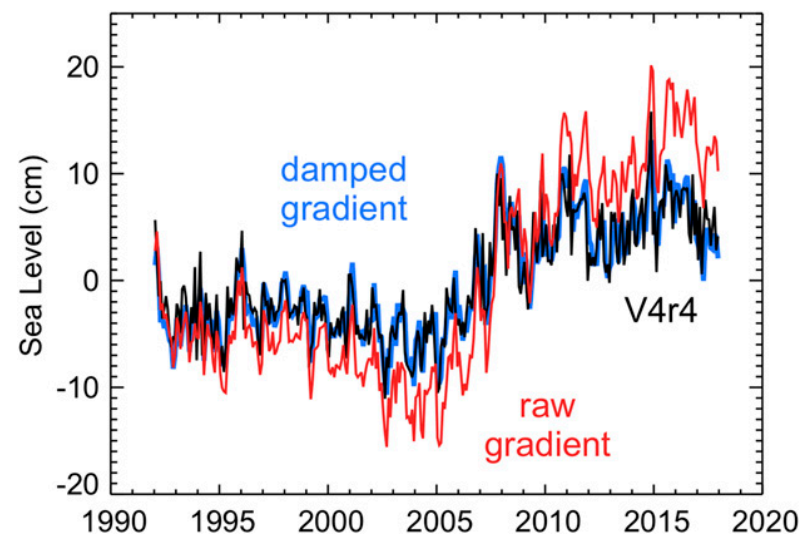

FIG. A4. Adjoint gradient reconstruction (red and cyan lines) of ECCO's surface stress-driven Gyre-mean sea level anomaly $(\mathrm{cm})$ (black; same as red in Fig. 5): the reconstruction using adjoint gradient with target instance December 2017 (red), and the same as red but with damped gradient (cyan; see the text for description).

surface-stress-driven reconstruction employing the gradient at $t_{g}=$ December 2017 (red) introduces a spurious low-frequency change absent in ECCO (black). Noting the nature of its errors, we apply a simple exponential damping to this gradient with an $e$-folding time scale of 76 weeks in lag. The resulting damped gradient (gray in Fig. A3) is in closer agreement with the model's forward sensitivity (black in Fig. A3) than uncorrected adjoint gradients are, and the same reconstruction using this modified gradient (cyan in Fig. A4) resolves the model's variation much more accurately than without the correction. Formally, the revised reconstruction explains $82 \%$ of ECCO's surfacestress-driven variance whereas the uncorrected reconstruction explains only $9 \%$. Last, the fact that a single gradient can explain most of the wind-driven variability suggests change in dissipation mechanism is not a major factor in Beaufort Sea's variation.

\section{REFERENCES}

Armitage, T. W. K., S. Bacon, A. L. Ridout, S. F. Thomas, Y. Aksenov, and D. J. Wingham, 2016: Arctic sea surface height variability and change from satellite radar altimetry and GRACE, 2003-2014. J. Geophys. Res. Oceans, 121, 43034322, https://doi.org/10.1002/2015JC011579.

—, G. E. Manucharyan, A. A. Petty, R. Kwok, and A. F. Thompson, 2020: Enhanced eddy activity in the Beaufort Gyre in response to sea ice loss. Nat. Commun., 11, 761, https:// doi.org/10.1038/s41467-020-14449-z.

Campin, J. M., J. Marshall, and D. Ferreira, 2008: Sea ice-ocean coupling using a rescaled vertical coordinate $z^{*}$. Ocean Modell., 24, 1-14, https://doi.org/10.1016/j.ocemod.2008.05.005.

Dee, D. P., and Coauthors, 2011: The ERA-Interim reanalysis: Configuration and performance of the data assimilation system. Quart. J. Roy. Meteor. Soc., 137, 553-597, https://doi.org/ 10.1002/qj.828.

Dickson, R. R., J. Meincke, S.-A. Malmberg, and A. J. Lee, 1988: The "great salinity anomaly" in the northern North Atlantic 19681982. Prog. Oceanogr., 20, 103-151, https://doi.org/10.1016/00796611(88)90049-3.

ECCO Consortium, I. Fukumori, O. Wang, I. Fenty, G. Forget, P. Heimbach, and R. M. Ponte, 2021: Synopsis of the ECCO
Central Production Global Ocean and Sea-Ice State Estimate, version 4 release 4. Zenodo, accessed 24 October 2019, https:// doi.org/10.5281/ZENODO.4533349.

Forget, G., J. M. Campin, P. Heimbach, C. N. Hill, R. M. Ponte, and C. Wunsch, 2015: ECCO version 4: An integrated framework for non-linear inverse modeling and global ocean state estimation. Geosci. Model Dev., 8, 3071-3104, https://doi.org/ 10.5194/gmd-8-3071-2015.

Fukumori, I., R. Raghunath, and L. L. Fu, 1998: Nature of global large-scale sea level variability in relation to atmospheric forcing: A modeling study. J. Geophys. Res. Oceans, 103, 5493-5512, https://doi.org/10.1029/97JC02907.

—, O. Wang, W. Llovel, I. Fenty, and G. Forget, 2015: A nearuniform fluctuation of ocean bottom pressure and sea level across the deep ocean basins of the Arctic Ocean and the Nordic seas. Prog. Oceanogr., 134, 152-172, https://doi.org/ 10.1016/j.pocean.2015.01.013.

Gaspar, P., Y. Gregoris, and J. M. Lefevre, 1990: A simple eddy kinetic energy model for simulations of the oceanic vertical mixing: Tests at station Papa and long-term upper ocean study site. J. Geophys. Res., 95, 16179-16193, https://doi.org/10.1029/ JC095iC09p16179.

Gent, P. R., and J. C. McWilliams, 1990: Isopycnal mixing in ocean circulation models. J. Phys. Oceanogr., 20, 150-155, https:// doi.org/10.1175/1520-0485(1990)020<0150:IMIOCM > 2.0.CO;2.

Giles, K. A., S. W. Laxon, A. L. Ridout, D. J. Wingham, and S. Bacon, 2012: Western Arctic Ocean freshwater storage increased by wind-driven spin-up of the Beaufort Gyre. Nat. Geosci., 5, 194-197, https://doi.org/10.1038/ngeo1379.

Gregory, J. M., and Coauthors, 2019: Concepts and terminology for sea level: Mean, variability and change, both local and global. Surv. Geophys., 40, 1251-1289, https://doi.org/10.1007/s10712-019-09525-z.

Griffies, S. M., and R. J. Greatbatch, 2012: Physical processes that impact the evolution of global mean sea level in ocean climate models. Ocean Modell., 51, 37-72, https://doi.org/10.1016/ j.ocemod.2012.04.003.

Kalnay, E., and Coauthors, 1996: The NCEP/NCAR 40-Year Reanalysis Project. Bull. Amer. Meteor. Soc., 77, 437-472, https:// doi.org/10.1175/1520-0477(1996)077<0437:TNYRP>2.0.CO;2.

Krishfield, R. A., J. Toole, A. Proshutinsky, and M.-L. Timmermans, 2008: Automated ice-tethered profilers for seawater observations under pack ice in all seasons. J. Atmos. Oceanic Technol., 25, 2091-2105, https://doi.org/10.1175/2008JTECHO587.1.

—, A. Proshutinsky, K. Tateyama, W. J. Williams, E. C. Carmack, F. A. McLaughlin, and M.-L. Timmermans, 2014: Deterioration of perennial sea ice in the Beaufort Gyre from 2003 to 2012 and its impact on the oceanic freshwater cycle. J. Geophys. Res. Oceans, 119, 1271-1305, https://doi.org/ 10.1002/2013JC008999.

Large, W. G., and S. Yeager, 2004: Diurnal to decadal global forcing for ocean and sea-ice models: The data sets and flux climatologies. NCAR Tech. Note NCAR/TN-460+STR, 105 pp., https://doi.org/10.5065/D6KK98Q6.

Losch, M., D. Menemenlis, J.-M. Campin, P. Heimbach, and C. Hill, 2010: On the formulation of sea-ice models. Part 1: Effects of different solver implementations and parameterizations. Ocean Modell., 33, 129-144, https://doi.org/10.1016/j.ocemod.2009.12.008. Marshall, J., A. Adcroft, C. Hill, L. Perelman, and C. Heisey, 1997: A finite-volume, incompressible Navier Stokes model for studies of the ocean on parallel computers. J. Geophys. Res., 102, 5753-5766, https://doi.org/10.1029/96JC02775.

McPhee, M. G., A. Proshutinsky, J. H. Morison, M. Steele, and M. B. Alkire, 2009: Rapid change in freshwater content of the 
Arctic Ocean. Geophys. Res. Lett., 36, L10602, https://doi.org/ 10.1029/2009GL037525.

Meneghello, G., J. Marshall, J.-M. Campin, E. Doddridge, and M.-L. Timmermans, 2018: The ice-ocean governor: Ice-ocean stress feedback limits Beaufort Gyre spin-up. Geophys. Res. Lett., 45, 11 293-11 299, https://doi.org/10.1029/2018GL080171.

Morison, J., R. Kwok, C. Peralta-Ferriz, M. Alkire, I. Rigor, R. Andersen, and M. Steele, 2012: Changing Arctic Ocean freshwater pathways. Nature, 481, 66-70, https://doi.org/ 10.1038/nature10705.

Noerdlinger, P. D., and K. R. Brower, 2007: The melting of floating ice raises the ocean level. Geophys. J. Int., 170, 145-150, https://doi.org/10.1111/j.1365-246X.2007.03472.x.

Proshutinsky, A., R. H. Bourke, and F. A. McLaughlin, 2002: The role of the Beaufort Gyre in Arctic climate variability: Seasonal to decadal climate scales. Geophys. Res. Lett., 29, 2100, https://doi.org/10.1029/2002GL015847.

—_, and Coauthors, 2009: Beaufort Gyre freshwater reservoir: State and variability from observations. J. Geophys. Res. Oceans, 114, C00A10, https://doi.org/10.1029/2008JC005104.

— water content in 2003-2018. J. Geophys. Res. Oceans, 124, 9658-9689, https://doi.org/10.1029/2019JC015281.

Rabe, B., and Coauthors, 2011: An assessment of Arctic Ocean freshwater content changes from the 1990s to the 2006-2008 period. Deep-Sea Res. I, 58, 173-185, https://doi.org/10.1016/ j.dsr.2010.12.002.

Redi, M. H., 1982: Oceanic isopycnal mixing by coordinate rotation. J. Phys. Oceanogr., 12, 1154-1158, https://doi.org/10.1175/15200485(1982)012<1154:OIMBCR>2.0.CO;2.
Regan, H. C., C. Lique, and T. W. K. Armitage, 2019: The Beaufort Gyre extent, shape, and location between 2003 and 2014 from satellite observations. J. Geophys. Res. Oceans, 124, 844-862, https://doi.org/10.1029/2018JC014379.

Spreen, G., R. Kwok, and D. Menemenlis, 2011: Trends in Arctic sea ice drift and role of wind forcing: 1992-2009. Geophys. Res. Lett., 38, L19501, https://doi.org/10.1029/2011GL048970.

Thompson, D. W. J., and J. M. Wallace, 1998: The Arctic oscillation signature in the wintertime geopotential height and temperature fields. Geophys. Res. Lett., 25, 1297-1300, https://doi.org/ 10.1029/98GL00950.

Timmermans, M.-L., J. Toole, and R. Krishfield, 2018: Warming of the interior Arctic Ocean linked to sea ice losses at the basin margins. Sci. $A d v$., 4, eaat6773, https://doi.org/10.1126/sciadv.aat6773.

Toole, J. M., R. A. Krishfield, M.-L. Timmermans, and A. Proshutinsky, 2011: The ice-tethered profiler: Argo of the Arctic. Oceanography, 24, 126-135, https://doi.org/10.5670/ oceanog.2011.64.

Watkins, M. M., D. N. Wiese, D.-N. Yuan, C. Boening, and F. W. Landerer, 2015: Improved methods for observing Earth's time variable mass distribution with GRACE using spherical cap mascons. J. Geophys. Res. Solid Earth, 120, 2648-2671, https:// doi.org/10.1002/2014JB011547.

Wunsch, C., 2006: Discrete Inverse and State Estimation Problems: With Geophysical Fluid Applications. Cambridge University Press, $371 \mathrm{pp}$.

- P. Heimbach, R. M. Ponte, and I. Fukumori, 2009: The global general circulation of the ocean estimated by the ECCOConsortium. Oceanography, 22, 88-103, https://doi.org/10.5670/ oceanog.2009.41. 